\title{
Massive Faculty Donations and Institutional Conflicts of Interest
}

\author{
Bart Kahr, Ph.D.' and Mark D. Hollingsworth, Ph.D.ii
}

\begin{abstract}
Most research universities have concrete policies for navigating the conflicts of interest of faculty members. Policies that might constrain university administrators acting on behalf of their schools, so-called institutional conflicts of interest, are absent or poorly developed at most places that could benefit from them. Researchers have argued for the illustration of institutional conflicts as a foundation for policy development. Here, we show the failure of research accountability when a faculty member made massive gifts to a leading American public research university, the University of Washington in Seattle, thereby creating allegiances that undermined commitments to academic values. Correspondence, some from thousands of pages acquired through the Washington State Public Records Act, show faculty colleagues, department chairs, deans, a provost, presidents, and the Board of Regents soliciting and accepting the donor's money but not sufficiently guarding the integrity of science when that was required. These records offer a rare look inside a university scientific misconduct investigation, a process typically shrouded in secrecy under the guise of confidentiality. They amount to a forensic analysis of what can go wrong with science at the nexus of a secret history of misconduct, spectacularly ambitious science, and large donations. The inabilities of federal and state authorities to reckon with institutional conflicts of interest are highlighted. The collective inaction can be understood within Lessig's framework of institutional corruption. The failings described herein are metaphorical holes in the safety net intended to protect the integrity of American science, a shared practice that is under increasing strain. All public records are available from the authors upon request. Those cited here are included in an appendix posted by the journal.
\end{abstract}

\section{Introduction}

Professors at institutions of higher education are occasionally dishonest in their work. A responsibility of college and university administrators is the confrontation and sanction of conduct by active faculty members that subjugate research and academic standards to other interests. Here, we document the response of one university when a multimillion-dollar benefactor with a record of research misconduct was accused of further misconduct. Administrators made consequential decisions while harboring competing interests, or what would be described as institutional conflicts of interest (ICOIs).

In the face of faculty misconduct, college and university administrators often respond swiftly and without equivocation. The Amherst College president, confronted with a professor's plagiarism, forecast "[T]he consequences are serious." ${ }^{1}$ The plagiarist resigned. The president of the University of Nevada at Las Vegas fired a plagiarizing literature professor, "effective immediately." 2 The interim president of the University of Utah went beyond committee-recommended sanctions of a dishonest professor: "[H]olding out the work of another as one's own... strikes at the very core of academic integrity...[T]he sanctions proposed...do not recognize the seriousness of this offense...[D]ismissal...is necessary to preserve the academic integrity of the institution and to restore public confidence." ${ }^{3}$

A different response to academic wrongdoing was made by officials of the University of Washington (UW), where one of the authors, hereafter BK, and Professor Larry R. Dalton, hereafter LD, were chemistry department colleagues from 1998-2009. LD's first publication in 1967, in the journal Inorganica Chimica Acta, ${ }^{4}$ contained words, pictures, and numerical data from the English language translation of a Russian paper published in $1965.5^{5}$ LD's paper was quickly retracted because "many of the experiments described were not actually performed." $6, i$ "ENP" is our abbreviation for this phrase, a euphemism used throughout in place of the words themselves repeated ad infinitum. In 2014, LD had another paper ${ }^{7}$ retracted $^{8}$ from the same journal, one

i Department of Chemistry and Molecular Design Institute, New York University, New York City, NY 10003 USA (bart.kahr@nyu.edu)

ii Department of Chemistry, Kansas State University, Manhattan KS 66506 USA (mdholl@ksu.edu)

Received: August 2018

Accepted for Publication: November 2018

Published Online: April 2019

(C) 2019 by the author(s). This article is distributed under the terms and conditions of the Creative Commons Attribution (CC BY) license. 
of several contemporaneous papers in which he published an invention being patented by others, including BK. In 2017, LD made a \$12 million donation to the UW department of chemistry, ${ }^{9}$ a sum on top of more than $\$ 10$ million he had already given. ${ }^{10}$ The UW president, Ana Mari Cauce, aware of LD's history, ${ }^{11}$ responded to the $\$ 12$ million as follows: "Larry Dalton has already made a phenomenal impact at the University of Washington, and to have a faculty member add to such a legacy by demonstrating this level of dedication to his field and to future generations of students and professors in the UW's chemistry department is truly remarkable." 9 This statement stands in sharp contrast to those of other presidents above.

Between the retraction and the donation described in the previous paragraph, there is likely a story worth telling. Few careers that begin so low end in adulation. Here, we fill in the gaps as best as we can with documents that include our correspondence and public records obtained by utilizing the Washington State Public Records Act. ${ }^{12}$ However, before telling this tale, we review the nature of ICOIs, a rising concern among academic ethicists. The meaning of ICOIs must first be appreciated so that the conduct of the UW can be read in the context of the relevant ethical principles as framed by academic experts.

\section{Institutional Conflicts of Interest}

A conflict of interest (COI) or apparent COI is a situation in which the impartiality of a decision maker is compromised or has a significant chance of being compromised in the eyes of an average observer because of incompatible loyalties, a primary interest, and a secondary interest that are seemingly irreconcilable. ${ }^{13}$ According to Logue and Shrank, "The possibility that conflicts of interest can lead to inappropriate decisions is recognized by nearly every profession and form of governance"... "[L]awyers physicians, journalists, governments, the financial industry...nonprofit corporations...national or international regulatory [bodies and] trade association[s] [have] imposed or recommended standards and disclosure requirements." ${ }^{14}$ COls of researchers and faculty members at universities have been widely studied. ${ }^{13,15,16}$

ICOIs, a newer frontier in ethics research and regulation, "occur when the institution or leaders with authority to act on behalf of the institution have COls that may threaten the objectivity, integrity, or trustworthiness of research because they could impact institution decision making."17 "Institutions" observed Resnik, "have all the necessary characteristics - duties, interests, and judgment - for having COls." 13 ICOI policies "lag well behind" those for individual COls, ${ }^{18}$ despite the fact that some experts consider the former to be more consequential. Resnik and Shamoo ${ }^{19}$ compared COls and ICOIs:
Since institutional COls can affect the conduct of dozens or even thousands of people inside and outside the institution, they have a potentially greater impact than individual COIs. Since institutional policies and actions set a standard of expected behavior for all individuals in the institution, the failure of the institution to hold to high moral standards can have a large corrosive effect on the conduct of its members.

Researchers have identified three categories of academic ICOIs: 1. university as firm, 2. sand and gravel, and 3. quid pro quo. ${ }^{20}$ When a university acts as a business or firm, conflicts can arise from commercialization activities. Managing "universities as firms may result in relationships that have the potential to influence decisions or have the appearance of influencing such activities." ${ }^{21}$ Sand and gravel refers to the use of the purchasing power of a large university to enrich particular contractors. Quid pro quo refers to exchanges or expectations of exchanges. Ethicists explicitly caution against "situations in which research, teaching, or service are compromised, or appear to be compromised, due to external financial or business relationships held at the institutional level by trustees or senior executives. Efforts to enhance external revenues, whether in the form of payments or donations..." can also lead to ICOIs. ${ }^{21}$ If, for example, a university administration improperly shields a major donor from scrutiny for conduct unbecoming an academic, its officers would be burdened with an institutional financial conflict of interest (IFCOIs). ${ }^{22,23}$ Any of the ICOI categories listed above may involve ill-advised transfers of money and could likewise be considered IFCOIs. "A single entity," observed Friedman, "cannot maintain research integrity while administering an institution's financial interest in research-related investments."22

The Association of American Universities ${ }^{24}$ first called attention to ICOIs because they put the most "fundamental responsibilities of universities" at risk, including commitments to education, academic freedom, and "advancing knowledge and understanding of the natural world and our human condition free from financial considerations." 25 Medical schools have taken leading roles in preventing ICOIs ${ }^{26}$ because such conflicts in the research hospital setting can have tragic outcomes. ${ }^{27,28}$ Needless to say, there is nothing, in principle, that limits ICOIs to the medical arena. The Associations of American Medical Colleges and American Universities recognized the generality of the problem when it said that "The existence (or appearance) of [ICOIs] can lead to actual bias, or suspicion of possible bias, in the review or conduct of research at the university. If [ICOIs] are not evaluated or managed, they may result in choices or actions that are incongruent with the missions, obligations, or values of the university." 29 Yet, policies addressing ICOIs have not been 
universally adopted. As of 2016, only 28\% of the top 100 American universities in research funding had ICOI policies. ${ }^{17}$

The first step toward mitigating the ill effects of ICOIs is to recognize that they exist. The next is to create effective policies that avoid the worst consequences. According to education researchers, the best practice is to publicize potential conflicts so that they can be monitored by all. ${ }^{20}$ Prominent listings of patents, copyrights, or trademarks held by universities are recommended. Besides disclosure, experts advocate a system of conflict management, empowering $\mathrm{COI}$ committees with external representatives having real authority, as well as the separation and prohibition of some institutional responsibilities. ${ }^{13,19,30}$

Donations to universities, on the other hand, are typically announced with fanfare to encourage imitators. Transparency, therefore, does not ordinarily play a significant role when ICOIs have their origins in donations from individuals. We are not aware of anything in the ICOI literature that directly addresses massive gifts by active faculty members.

As emphasized by Caplan and Redman, "there is no detailed federal policy in the USA on identifying or managing institutional conflicts of interest." ${ }^{\prime \prime 1}$ In the absence of guidance, some universities have nevertheless taken the lead. Pennsylvania State University (PSU) has good reasons for advertising a well-developed ICOI policy, given the tumultuous events related to its failure to shield children from abuse in order to protect its football program. ${ }^{32}$ We liberally quote from PSU's explicit IFCOI policy because it will serve as a point of reference as our story unfolds.

Institutional financial interests can be created by gifts, payments, royalty income, equity and other financial benefits from or interests in for-profit entities... When an institutional conflict of interest is identified, a management plan will be implemented to manage, reduce, or eliminate the institutional conflict. The University's Institutional Conflict of Interest Committee shall review and evaluate the financial or business interests of the University or of University Officials to identify potential institutional conflicts of interest; shall create... plans to manage, reduce or eliminate institutional conflicts of interest... The University will strive to manage or eliminate each institutional conflict of interest identified before any contract, sponsored project, dedicated gift, or transaction is executed; any contractual relationship is initiated; or any action is taken that might be inappropriately affected or appear to be inappropriately affected by the institutional conflict of interest... As a steward of public funds, the University strives to ensure that its research, teaching, outreach, business transactions and other activities are not inappropriately affected by, nor appear to be inappropriately affected by, the financial or business interests of the University or of University Officials... [T]he
University will not allow its financial or business interests, or the financial or business interests of University Officials, to compromise the integrity of the University's primary mission or to inappropriately influence decisions regarding University Activities...

...Institutional Financial Interests [can be]...

Royalty arrangements: payments, including royalty payments and licensing fees, resulting from technology transfer, licensing, and business activities that, for each arrangement, exceed $\$ 100,000$ in the preceding twelve 12-month period;

...[E]quity and ownership interests of any amount in any for-profit entity that is not publicly traded:

...[E]quity and ownership interests valued at greater than $\$ 100,000$ in the preceding twelve 12 -month period in any publicly-traded, for-profit entity...

Gifts greater than one million dollars $\$ 1,000,000.00$ from any for-profit entity or philanthropic unit associated with a for-profit entity. ${ }^{33}$

This statement empowers a university ICOI committee, emphasizes the necessity of identifying ICOIs, and specifies processes to reduce or eliminate ICOIs. It gives specific examples of ICOIs, including gifts.

Apart from some reactive institutions such as PSU, it is generally recognized that the creation of ICOI policies at the majority of universities that do not have them is unlikely without federal intervention or guidance. ${ }^{17}$ The Inspector General of the Department of Health and Human Services has urged institutions to establish processes for establishing whether financial interests rise to the level of ICOIs, ${ }^{34}$ but this request has not been widely implemented.

\section{Deviations from Accepted Practice 1967}

Larry R. Dalton's first retracted paper ${ }^{4}$ was co-authored with L. A. Dalton and L. L. Dalton. (The three authors are distinguished only by their middle initials.) The Daltons purportedly showed how highly reactive electrons of sodium, potassium, and rubidium atoms absorbed microwave radiation at low temperatures in an applied magnetic field. The paper was immediately retracted because of "ENP." ${ }^{6}$ Where, then, did the data come from if the experiments were not performed? Figure 1 shows an overlay of spectra (graphs of energy absorbed $-y$-axis versus external magnetic field $-x$-axis) ostensibly recorded in the USA and in the USSR. Random electronic noise is mimicked bump for bump in the overlay. ${ }^{4,5}$ It is impossible to have identical patterns of stochastic electronic noise in different experiments. ${ }^{35}$ The reader is left to speculate as to how graphs purportedly recorded on different instruments and on different continents can resemble each other with such fidelity. 


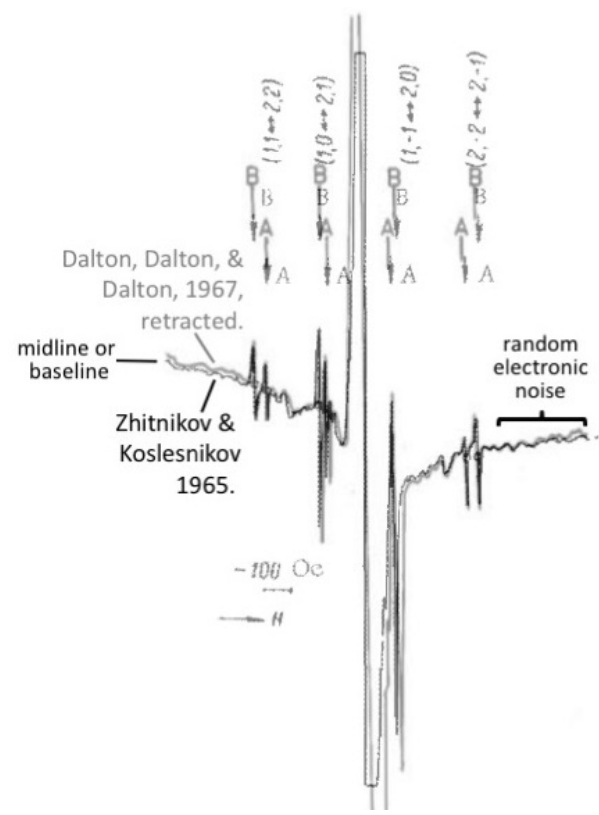

Figure 1: Overlay of spectrum in Zhitnikov and Kolesnikov ${ }^{5}$ with that of Dalton et al., ${ }^{4}$ later retracted. ${ }^{6}$ Reproduced with permission of Elsevier, and of Soviet Physics - Solid State, under annual license with the Copyright Clearance Center.

Over $70 \%$ of the passages in the paper by Zhitnikov and Kolesnikov ${ }^{5}$ were repeated, almost verbatim, in Dalton et al., ${ }^{4}$ as exemplified by the following pair:

Zhitnikov and Kolesnikov, 1965: It may be assumed that the sodium atoms, for which two types of capture locations occur, are stabilized in a substitutional position of the benzene lattice, and in an interstitial site, in the center of a somewhat distorted octahedron, while the potassium and rubidium atoms, which are of larger size than the sodium atoms, are only stabilized in the substitutional position, where there is more room than in the octahedral position...

The fact that no monotonic character is observed in the matrix shifts on going from sodium to potassium and from potassium to rubidium is not inconsistent with the theoretical ideas...since the increase in the negative shift resulting from an increase in the polarizabilities in the order $\mathrm{Na}, \mathrm{K}, \mathrm{Rb}$ may be made up for by the positive contribution to the matrix shift, which increases with increase in the size of the atom in the series of alkali metals. ${ }^{5}$

Dalton et al., 1967: It may be assumed that the sodium atoms, for which two types of capture locations occur, are stabilized in a substitutional position of the benzene lattice, and in an interstitial site, in the center of a somewhat distorted octahedron, while the potassium and rubidium atoms, which are of larger size than the sodium atoms, are only stabilized in the substitutional position, where there is more room than in the octahedral position...
The fact that no monotonic character is observed in the matrix shifts upon progressing from sodium to potassium and from potassium to rubidium is not inconsistent theoretical concepts...since the increase in negative shift resulting from an increase in the polarizabilities in the order sodium, potassium, rubidium may be compensated by the positive contribution to the matrix shift, which increases with increasing size of the atom in the series of

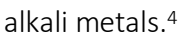

Highlighted verbatim passages and a paragraph-byparagraph comparison of reference 4 and reference 5 are provided in the Appendix. ${ }^{36}$

Dalton et al. reported certain physical constants ( $g$ - and $a$-values) they claimed to have measured. As shown in Figure 2, each of the eight values reported in the first four lines of Table III of Dalton et al. (Figure $2 \mathrm{~B})^{4}$ is identical to the number given in Table 1 of Zhitnikov and Kolesnikov (Figure 2A). ${ }^{5}$ The only differences are the estimates of the errors in measurement. The probability that $1438.8 \pm 5.7$ will come out to be 1438.8 in a second measurement is very small, less than $1 \%$, assuming that the errors are random and normally distributed. The probability that eight values in Figure $2 \mathrm{~A}$ are the same in $2 \mathrm{~B}$ is the product of eight small probabilities calculated from the errors reported by Zhitnikov and Kolesnikov. ${ }^{5}$ We estimate that the probability of all eight numbers being identical to within the reported precision is approximately one part in 20 trillion (1 in 20,000,000,000,000).ii

(We have tried to be faithful to the science for readers with an appropriate background while trying to use plain language for others not so equipped. However, the scientific details are not necessary for appreciating the ethical issues that are discussed.)

A. Data from Table 1 of Zhitnikov and Kolesnikov(5)

\begin{tabular}{|c|c|c|c|c|}
\hline & Atom & ty. Mc & $\frac{\delta(\lambda v)}{\Delta \times \text { free }}$, & ${ }_{j}$ \\
\hline $\begin{array}{l}\mathrm{Na}^{23} \\
\mathrm{Na}^{23}(\dot{B}) \\
\mathrm{K}^{39}{ }^{*} \\
\mathrm{Rb}^{85} \cdot 5^{*} \cdot\end{array}$ & 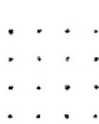 & $\begin{array}{l}438.8 \div 5.7 \\
615.9 \div 5.7 \\
363.4 \div 1.0 \\
450.4 \div 10.8\end{array}$ & $\begin{array}{r}-18.8 \\
-8.8 \\
-21.3 \\
--19.3\end{array}$ & $\begin{array}{l}2.0029 \pm 0.0006 \\
2.0036 \pm 0.0006 \\
2.0024 \pm 0.0008 \\
2.0046 \div 0.0012\end{array}$ \\
\hline
\end{tabular}

\section{B. Data from Table III of retracted paper by Dalton et al.(4)}

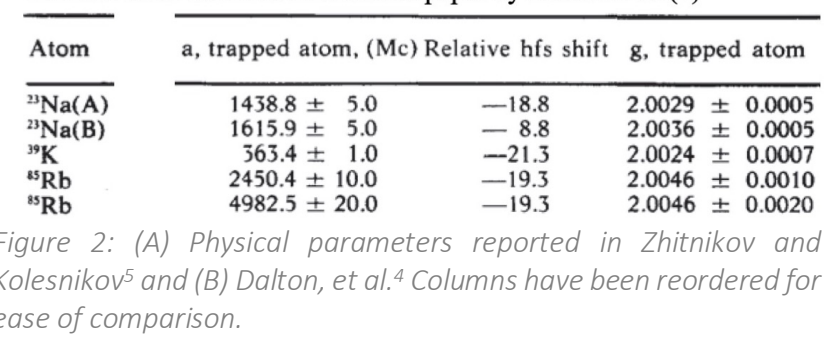


Inorganica Chimica Acta's retraction notice remarked that LD was acting under "extreme strain" at the time. ${ }^{6}$ According to the historian Judson, "Fabrication, falsification, plagiarism - all three are fraud." 37 "The only ethical principle which has made science possible," said another young spectroscopist, C. P. Snow, speaking for one of the characters in his first novel, "is that the truth shall be told all the time. If we do not penalize false statements made in error, we open up the way, don't you see, for false statements by intention. And of course, a false statement of fact made deliberately is the most serious crime a scientist can commit." 38 ,iii

In the age before easy electronic communication, retraction notices published in obscure journals sat yellowing in bound volumes, removed from public scrutiny. Thus, LD's 1967 publication did not preclude a university career. LD obtained his Ph.D. from Harvard University, held a first faculty appointment at Vanderbilt University, was granted tenure, moved to the State University of New York at Stony Brook, then to the University of Southern California, and finally to the UW in 1998. In 2003 and 2011, he won national awards from the American Chemical Society ${ }^{39,40}$ and has been described as a Nobel Prize nominee. ${ }^{41}$

At least one member of the UW chemistry faculty, Professor Bruce Robinson, LD's Ph.D. student at Vanderbilt University, knew of LD's spectral skeletons (Figure 1). In 2012, Robinson wrote to a Vanderbilt University professor, a colleague of LD's in the 1970s:

Regarding [redacted]s mistake [the retracted 1967 article $\left.{ }^{4,6}\right]$, he should have known better. It was irrelevant whether you knew about it because Harvard said he was a trained scientist and Harvard dealt with the issue at the time. So if they were able to handle it and put it behind them, then it is not up to anyone else to further consider the matter. 42

The Vanderbilt professor told BK, "We were not aware of this publication ${ }^{[4]}$ when we hired [LD], nor of its 'retraction'[6]."43

LD was recruited to Seattle in 1998 by Robinson and UW Professor Alvin Kwiram, ${ }^{44}$ LD's Ph.D. mentor at Harvard between 1967 and $1971 .{ }^{45}$ Kwiram was acknowledged in the retracted 1967 paper.

\section{0}

In 1998, none of BK's new colleagues acknowledged to him that they were knowingly recruiting a faculty member with a record of publishing "ENP."

Shortly after arriving at the UW, LD announced to the Seattle Post-Intelligencer that he had synthesized a material that would change the world, a material that could be used as a switch for light, thereby speeding up the internet, a socalled organic electro-optic polymer that, in LD's words, would "dominate the $21^{\text {st }}$ century" 46 and transform the economy of the Pacific Northwest. ${ }^{47}$

A

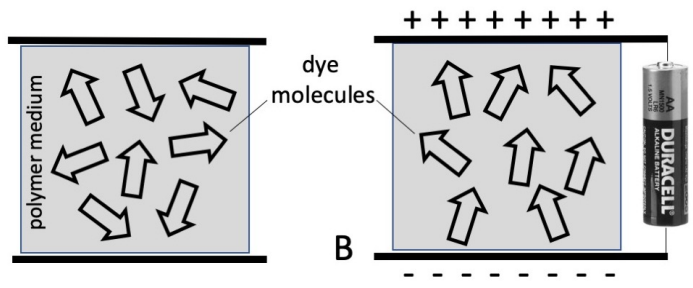

Figure 3: Schematic diagram showing a random arrangement of dye molecules (A) and alignment of dye molecules in an electric field (B). The arrows represent the dipole moments of molecules with a different top and bottom. "Poling efficiency" is a measure of the extent of alignment of the dye molecules (arrows) with an applied electric field. The field is supplied by a power supply. In this scheme, the 1.5-volt Duracell battery is merely illustrative. Typically, one supplies 100 volts across a very narrow polymer film whose thickness is one micron (one-millionth of a meter).

An organic electro-optic polymer is a plastic-like material that can be applied to surfaces as thin films. Such materials can be made to retard the velocity of light traveling through them if a small electrical potential is applied. By modulating the speed of light with electrical signals, information could be translated into faster optical signals carrying more information. The control of light particles (photons), as opposed to electrons, is called photonics, in lieu of electronics. The key advance described in the newspaper was a newfound ability to align dye molecules in thin polymer films: "With the improved alignment, the team was able to achieve the high speed and low voltage they wanted," according to the reporter. ${ }^{46}$ In a nutshell, the most desirable properties exhibited by an electro-optic polymer rely heavily on the "poling efficiency" of dyes in electric fields, that is the extent to which molecules represented by arrows in Figure 3 can be made to line up in more or less the same direction in an applied electric field.

LD raised over $\$ 100$ million in grants, contracts, and venture capital to realize his vision..$^{48,49,50}$ He forecast that "The technology developed [with this support] should have a significant economic impact on the Seattle area and the nation." ${ }^{11}$ During this period, large sums of money were spent on the synthesis of dye molecules whose shapes, LD and coworkers had predicted, ${ }^{52,53,54}$ would make them especially prone to alignment.

\section{3-04}

Part of the large investment ${ }^{\text {iv }}$ in LD and the UW was $\$ 36$ million from the National Science Foundation (NSF) for a Science and Technology Center (STC) that was active from 2002 to 2013 and was led by LD during its first five years. ${ }^{55}$

In 2003, BK received a $\$ 40,000$ subcontract from this center. On first examining some of LD's materials, it was 


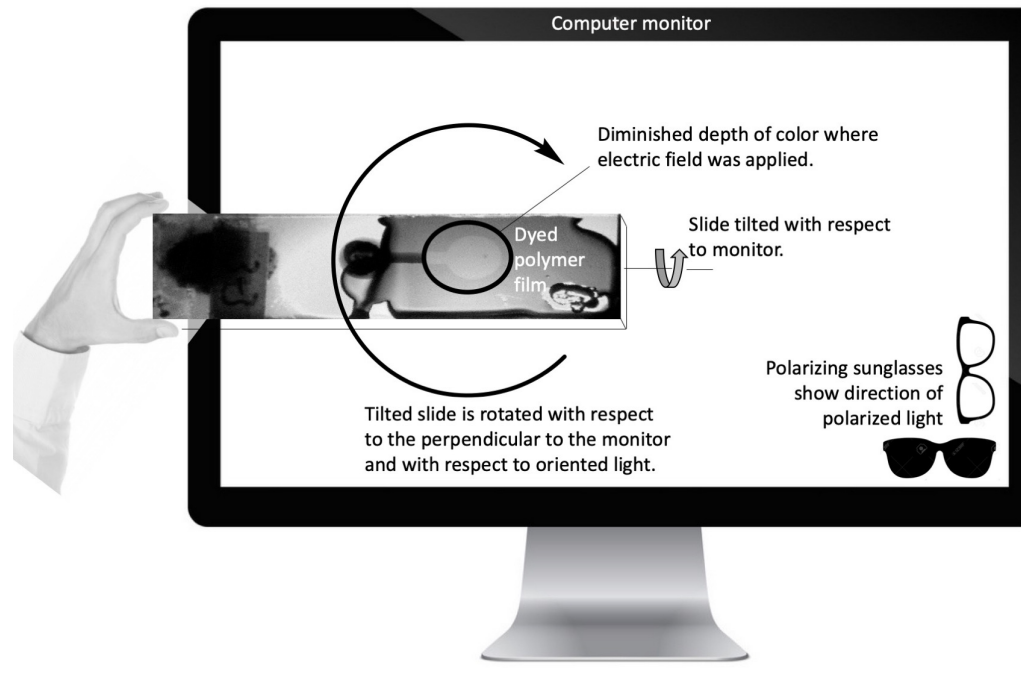

Figure 4: Electro-optic film of the kind expected to "dominate the 21st century" 46 by virtue of orienting dyes, held in front of horizontally polarized light emitted from a computer monitor. The orientation of polarizing sunglasses can be used to assay the direction of the light polarization. Tilting the film with respect to the flat screen, and then rotating it around a perpendicular axis was expected to change the depth of transmitted color active region within the black circle where the electric field was applied. This area was always lighter, and of a different color hue, suggesting chemical degradation and transformation caused by the applied electric field. ${ }^{75,78}$ The eye is a very sensitive light detector. No detectable change in color depth upon reorientation of the sample with respect to the monitor means few molecules were oriented. In all samples we investigated, there was obvious decomposition and no change in appearance upon rotation. Curiously, we have never seen a photograph (as exemplified above) in any UW publication of the kinds of samples that we were able to acquire. In all samples that BK investigated, the region of interest was always lighter and not evidently responsive to polarized light.

immediately obvious to BK that they did not have strong dye alignment, as reported in the Seattle Post-Intelligencer. ${ }^{46}$ The materials did not show linear dichroism, 56,57,58,59,60 the change in the absorption of light with respect to a polarized light source (Figure 4). (Polarizing sunglasses work because they are responsive to polarized light reflected from horizontal surfaces such as wet roadways and bodies of water.) Linear dichroism was a prerequisite for the ordering of dyes that was presumed to be necessary for the materials to act as efficient light switches. $61,62,63,64,65,66,67,68$

In 2004, LD's team had never made measurements of linear dichroism, a phenomenon that was first observed in thin films of dyes in the middle of the $19^{\text {th }}$ century. ${ }^{69,70} \mathrm{BK}$ began to make urgent requests to focus the attention of the leading investigators in the center on the question of dye orientation. These requests were ignored. BK appealed to Kwiram, a former Vice Provost for Research with high stature at the UW. Kwiram had become the executive director of LD's NSF center. In 2004, BK told Kwiram, among many others, that the center's science was wrong at its heart and that nobody would act. ${ }^{71}$ The absence of dye alignment placed severe limitations on the electro-optical response that the devices could have been expected to give at the time. ${ }^{61,62,63,64,65,66,67,68}$ Kwiram advised BK to "moderate our importuning" because "some of the team is a bit impatient with the issues you raise." The principals, Kwiram said, could "worry about understanding and explaining it after they get the grant ${ }^{v}$ renewed. There is a lot riding on this right now."72 Earlier that year, the chemistry department chair Paul Hopkins admitted to BK that "we would be in bad shape if anything untoward happened to the STC [LD's Science and Iechnology Center]." 73

In 2004, BK wrote to Alex K.-Y. Jen, a professor of materials science and a "Thrust Leader" of the NSF center: "I am very concerned about this question of dye reorientation. We want to get out in front of this ASAP. How do you want to proceed? I need samples - lots of them - to make sure that the destruction with [sic] see is general and representative. Ideally, it would be good to have a series where the [electric] poling field and poling time are varied systematically." 74 We received five samples $a$ year later after continuous prodding, hardly sufficient for the analysis proposed, and hardly responsive to the urgency of the problem.

BK was obliged to write a report for the NSF at the end of the 2003-4 fiscal year. ${ }^{75}$ The report said what should have been obvious to a scientist in possession of any of LD's samples and a computer monitor (Figure 4): "[Molecular orientation] has to the best of our knowledge been adopted tacitly without explicit experimental evidence for dynamic processes... We have shown that the model for [electro-optic] activity in polymers resulting from dye reorientation needs considerable refinement... By challenging the mechanism, our work will have great impact on the synthetic effort, carried out at great cost." 75 This was a serious statement that could no longer be ignored.

Subcontractor progress reports are submitted to the center leadership so that they can be synthesized into a coherent albeit representative document that is then forwarded to the NSF. BK's report was submitted to Jen, ${ }^{76}$ but none of his urgencies were communicated to the NSF, even though the NSF requires specification of "impediments" encountered in research. ${ }^{77}$ (See Adjudications section.)

Subsequent to BK's original failure in January 2004 to observe linear dichroism in LD's films, BK's Ph.D. student, 
Jason Benedict, now an Associate Professor at the University of Buffalo, ${ }^{78}$ began a more sustained study in March 2005 with the aforementioned five samples. Benedict could not characterize the linear dichroism, even with instruments optimized to measure it. Benedict wrote in his dissertation, "The somewhat haphazard collection of experiments discussed in this chapter was the consequence of the great difficulty we experienced in getting systematically prepared samples from colleagues that were necessary for a proper study of the linear optical properties."78 The materials we had obtained by this time showed changes in hue and inhomogeneities after applying a strong electric field. Moreover, they were unstable while illuminated, fading like book jackets in the sunlight, albeit quickly. This suggests chemistry/decomposition, something clearly flagged as an "impediment" by two of the STC leaders, Professor Seth Marder from the Georgia Institute of Technology and Jen, in a publication in 1998. They wrote with coworkers, "[T]he materials must have low optical losses from either absorption or scattering, and they must be environmentally and photochemically stable if they are to be of practical use." 79

BK had won his subcontract in part by designing better light-absorbing molecules for electro-optic polymers under the expectation in 2003 that such molecules could be highly aligned. The newly designed molecules were synthesized and evaluated in BK's laboratory by research scientist Dr. Sei-Hum Jang. BK and Jang had worked together since the early 1990 s, $^{80,81,82}$ but in 2003, BK could no longer afford to pay Jang's salary, as often happens when research awards wax and wane. Jang, an expert at synthesizing dye molecules, and orienting them -- not in polymers, but in crystals ${ }^{83,84}$-- was hired by Jen. Before Jang had relocated to the materials science department, BK and Jang were discussing the dye molecules that Jen wanted. In that conversation, BK and Jang predicted that the dye performance in electro-optic devices could be much improved by switching out certain atoms for others. These new compounds were called the TCP dyes or chromophores, a chemical nickname. Jang quickly synthesized several of them. All indications suggested that if they could be oriented, they would be superior as components of light switches. Based on their initial promise, students in the Dalton and Jen labs were soon engaged in synthesizing and analyzing these compounds.

Jang and BK soon filed an invention disclosure, and a United States patent was ultimately awarded. ${ }^{85}$ Jen, now supporting Jang from his research grants, attached his name to the patent application without discussion. Regarding the provenance of the invention, Jang wrote to LD (and Jen, among others) in early 2005, "I do work for Professor Jen, and Professor Kahr is a co-inventor of the chromophore [dye]." ${ }^{86}$ In March of 2003, BK invited LD to his laboratory so that Jang could describe his work. BK wrote to Jen, "I just met Larry in the latte stand and we had a very nice chat. I took him by the lab and reintroduced him to Sei-Hum [Jang] who gave him an update on the work [the invention of the TCP dyes] and he was apparently delighted." ${ }^{87}$ LD requested the structures of the molecules synthesized and computed predictions of their light-matter interactions; they were happily provided by Jang. ${ }^{87,88,89}$

Then, in 2004 and 2005, LD published six papers, one in Inorganica Chimica Acta $^{7}$ and five others ${ }^{90,91,92,93,94}$ on this new (TCP) composition of matter without the knowledge of $B K$ and without the knowledge of Jang in at least some cases. In January 2005, Jang stumbled across one of these papers ${ }^{7}$ and was surprised to find that he was listed as a coauthor, even though he had no knowledge of the publication. Jang accused LD in an email of abusing his authorship rights and the NSF principles outlined in the online Responsible Conduct of Research (RCR) course that all investigators participating in LD's center were required to complete. Jang complained, "As we all learned from courses in 'RESPONSIBLE CONDUCT OF RESEARCH DISCUSSION SERIES', it is a major breach of scientific ethics for publishing a paper with your name on it about which you were never consulted." 86,95 LD stated that he disagreed with Jang's assertions. ${ }^{88}$ Jang challenged LD to defend his denial: "If you disagree with what I said, please state what you disagree [with] in writing, so every interested party can see it clearly." 86 Their correspondence abruptly ended.

Jang, a father of three, was reliant on the support of LD's center. ${ }^{96}$ Much later, Chemical \& Engineering News correctly reported that when Jang brought these authorship abuses to LD's attention in 2005, he was "rebuffed."97 The magazine reported that LD had "given responsibility for the paper to two graduate students [Firestone and another], one of whom didn't realize the history of the chromophore's development." 97 LD's account, however, does not explain the provenance of five other papers on TCP dyes, ${ }^{90,91,92,93,94}$ one of which had no co-authors to blame. ${ }^{83}$ In 2010, LD wrote to Dean Cauce, "I wish that Professor Kahr had called his concern to my attention earlier as it could have been resolved much more quickly"98 and to Chair Hopkins, "Dr. Kahr's contribution was not called to my attention." 99 This is false. Jang had brought it directly to LD's attention early in 2005, and that conversation had been memorialized in emails that were provided to dozens in the UW administration. If for any reason LD was unsure who invented the thing he was disclosing, it was his responsibility to find out.

Four of the six papers, ${ }^{91,92,93,94}$ were published by SPIE, The International Society for Optics and Photonics, and were also considered for retraction. Eric Pepper, Director of SPIE Publications, chose not to act. He said, "Retracting one or more of these papers as an outcome of this inquiry would 
be a very consequential action on SPIE's part and would not go unnoticed."100 Pepper asked LD his opinion, and replied, "Professor Dalton claims he was not well informed about your role in the development of the chromophore material." 100 Pepper had the correspondence that showed LD's claim was untrue, but he deferred to LD, an SPIE Lifetime Achievement Award winner. ${ }^{101}$

\section{6-08}

In 2006, chemistry professor Phil Reid had confirmed in sensitive experiments on single molecules what we had seen by looking; dye molecules were poorly ordered and subject to degradation. ${ }^{102}$ Later, he wrote to BK, Robinson, Hopkins, and others, "[S]ingle-molecule work from my group demonstrated that the field-induced perturbation on the chromophore [dye] rotational dynamics were very modest...this paper blew a relatively large hole [enlarged an existing hole] in the belief that the poling field provided a serious alignment potential." He continued, "I would argue the most important scientific contributions in this field have come from workers performing fundamental research. At the very least, we serve as quality control on 'powerpoint engineering'. That quality control is critical (largely ignored as it may be)." 103 In a follow-up e-mail, Reid continued, "Alex [Jen] was given the results of our single-molecule studies in 2005 and 2006, and chose to include none of it in the annual reports to the NSF, nor to present the work to the site visit panels." 103

In our view, measurements by BK and Reid go well beyond "quality control." The absence of dye alignment, according to author Mark D. Hollingsworth (hereafter MDH), "placed severe limitations on the electro-optical response that the devices could have been expected to give at the time." 61 The literature at the time said as much, ${ }^{62,63,64,65,66,67,68}$ and referees of a renewal proposal for the STC, as well as NSF program officers, would have understood this to be the case. We therefore argue that Kahr and Reid's results put at risk a well-funded enterprise (the NSF Center, related grants on similar subjectsiv, ${ }^{i v}$ and LD's company). The Center's failure to report Reid's single-molecule studies showed that "fundamental" unwelcome scientific evidence was withheld in at least two instances.

The UW'S NSF Science and Technology Center was renewed for $\$ 17,976,000$ in 2007. In 2008, BK accepted a faculty position at New York University (NYU) since it had become increasingly difficult to witness such pervasive indifference to demonstrable scientific facts. He left Seattle with his wife and son in 2009.

\section{9-11}

During the time that BK was preparing to leave the UW, Robinson recognized that in order to make good electrooptic materials, dye molecules do not have to be very strongly oriented after all, contrary to what had been said and expected during the previous decade. He and others wrote a paper about this newfound understanding, unbeknownst to us. ${ }^{104}$ BK saw it in 2010 and wrote to Robinson from New York:

A few evening [sic] ago I stumbled across [your recent paper]... I do have two criticisms:

1. Not until the very last line do we discover that mistakes were made: the "order in the material is much lower than anticipated from previous estimates". Few of readers of any technical paper make it to the very last line, and just a fraction of these has the background needed to read between lines. Your presentation, in my view, is built to conceal.

2. My name is hijacked as an endorsement. [In the acknowledgment, they say, "We thank Bart Kahr for helpful discussions"]. After the frank discussions we shared, the idea that I would be honored by this infelicitous history caught me by surprise... That the order is "much lower" than previously published is not a new discovery. We have been shouting as much, in vain, for seven years. This is said most plainly in my suppressed 2004 sub-report to the NSF.

Reid, who was cc'ed in the correspondence, replied:

I think it was clear to all of us that the extent of acentric order [a measure of dye reorientation] was not remotely close to what was being assumed, and I think this was clear from at least 2004...I'll [prepare an erratum] and get something that is acceptable to all. I know you're upset, but try to remember I'm on your side on this issue... I'm not trying to say, "I'm on it; don't worry." Those that should be listening would rather not. It is entirely frustrating, and I worry a lot about the ethics involved. It is something I hope to have the opportunity to change...I absolutely agree that the 'shoot first, ask questions later' approach is poor science. I have been asked...about your concerns, and have supported them as entirely legitimate."103

In 2011, Reid, LD, and Robinson, among others, conceded, ${ }^{105}$ at BK's insistence, that it was long known that the dye order was very small long before their \$18 milliondollar grant renewal in 2007, and they provided three citations, an accurate attribution, at long last:

(5) Kahr, B. Private communications (from 2003 through 2009); University of Washington, 2003.

(6) Kahr, B. "Report intended for NSF via the Materials and Devices for Information Technology Research"; MDITR, Science and Technology Center, University of Washington, 2003 [see appendix reference 75].

(7) Benedict, J. Dyeing Crystals: $19^{\text {th }}$ Century Phenomenology to $21^{\text {st }}$ Century Technology; University of Washington: Seattle, WA, 2007. ${ }^{[78]}$

However, large sums of money were won between BK's report and these concessions. LD's center was expiring and 
could not be renewed. Interest in polymer electro-optic materials had waned. A fuller, more accurate and honest accounting could not jeopardize future funding.

\section{2}

In 2012, BK gave a public lecture at the annual meeting of the American Crystallographic Association in Boston about the suppression of NSF results and the justification of these omissions by the UW administration (See Adjudications section). ${ }^{\text {vi }}$ The lecture was picked up by Nature, the world's premier science publication. Jen told Nature's reporter, Eugenie Reich, "there was no effort to omit Kahr's results because they challenged an aspect of the centre's research." ${ }^{176}$ This sentence is begging for another clause: "they were omitted because..." There is no such clause. Kwiram remarked, "This issue [of the mechanism of electrooptic activity] was like a mosquito buzzing around and it was like don't bite me right now when we've got bigger fish to fry." "76 Robinson told Nature, "Bart was right...but so what?"76

Department chair Hopkins asked Robinson about whether Nature's reporting might hurt their chances of obtaining even more funding: "[I]'Il presume you see nothing in the report that you think has any substantial probability of damaging future funding requests." ${ }^{106}$

Shortly thereafter, BK received an email from the aforementioned Vanderbilt professor. It contained the 1967 retraction notice, which changed everything, as far as we were concerned, by putting our experience in a new light. It revealed that LD had once published "ENP" in a relatively obscure journal, Inorganica Chimica Acta, the same journal in which LD had already published BK's work without his permission in 2004. BK then requested the retraction of the 2004 article, $^{7}$ which was subsequently withdrawn. ${ }^{8}$ The website RetractionWatch.com titled its post "Leading chemist notches two retractions in one journal, separated by 47 years." 107

\section{4-16}

The 1967 retraction notice of "ENP" did not apprise us of the words, pictures and data taken from others because it had cited the wrong page (1175, not 1157) of the wrong journal (Fizika Tverdogo Tela). ${ }^{6} \mathrm{MDH}$ showed that the English translation of the Russian journal, Soviet PhysicsSolid State, ${ }^{6}$ was actually the source of the content that had appeared in Inorganica Chimica Acta, and which formed the basis of the eye-popping comparisons in Figures 1 and 2 .

In 2015, when news reports forecast that interim UW president Cauce was about to be named president, ${ }^{108} \mathrm{BK}$ wrote to the Board of Regents ${ }^{109}$ to inform them that their top candidate had been defending a scientist who had published "ENP" and from whom she had solicited and received large sums of money (See Adjudications section.) BK suggested that in his view, such a president, however qualified and admired, could put a public university at risk. At this time, Phyllis Wise, the Chancellor of the University of Illinois at Urbana-Champaign, formerly interim UW president from 2010-11, was under scrutiny for hiding emails about the firing of a controversial professor at the behest of donors. Wise was forced out, disrupting a large community in a painful process. ${ }^{110}$

BK provided Figure 1 among other details to the Regents, and $\mathrm{cc}^{\prime}$ ed the letter to $c a$. 50 department chairs in the College of Arts and Sciences, because he was well aware by this time that the UW administrators would not reply to any matter regarding LD. ${ }^{111}$ He did not receive one response from the ca. 50 department chairs who were shown Figure 1. On March 23, 2015, the dean of the college, Robert Stacey, advised the faculty that BK's concerns were "without merit" and "without foundation."112 Stacey was also shown Figure $1 .{ }^{113}$ The previous day, March 22, Stacey wrote to LD, "Your continued support provides our faculty with otherwise unavailable opportunities to pursue their research in ways that also enable them to lead our students toward a bright and strong future, where they can pursue new areas and challenging scientific goals." ${ }^{114}$ The next year, he wrote, "It is often said, but rarely with as much truth, that we simply couldn't do it without you."115

The impact of $L D$ and the UW on the $21^{\text {st }}$ century, now almost 20 years in, could use an independent assessment. Former Provost Lee Huntsman forecasted in 2002 that we "expect the state and region to become industry leaders" in photonics. ${ }^{51}$ Are they now? We tried to follow Lumera Corp., the company LD founded as a subsidiary of Microvision, Inc. in 2000. In 2007, Lumera was acquired by the Bothell, Washington firm GigOptix, which for a time apparently commercialized polymer based electro-optic light switches. ${ }^{116}$ GigOptix became GigPeak in a merger that in 2014 joined with a Brazilian company to create BrPhotonics Produtos Optoeletrônicos LTDA in Campinas, transferring to the Brazilian venture its polymer technology along with equipment worth $\$ 459,000 .{ }^{117}$ Lightwave Logic of Colorado bought BrPhotonics in 2018: "The \$350,000 deal brought 15 polymer chemistry materials, devices, packaging, and subsystems patents." 118

The aforementioned sums seem to us like a thin legacy of a ca. \$100 million investment and not at all consistent with UW hyperbole about a disruptive technology. The hyperbole continues in a recent article by Kwiram called "The Next Big Thing."119 LD wrote a book about Organic Electro-Optics and Photonics (2015) with four other scientists, ${ }^{120}$ that states that "[T] he commercial potential of organic-electro-optics for next-generation information technology is becoming increasingly recognized." Compare with 2000: "will dominate the $21^{\text {st }}$ century." ${ }^{46}$ According to 
an independent market analysis in 2018, the future of electro-optic light switches based on inorganic crystals is bright, and the prospects for polymers rest with the aforementioned Lightwave Logic, ${ }^{121}$ which is not associated in any way with LD and the UW.

\section{Donations}

Fifty years after the events of 1967 described above, LD and his wife, Nicole Boand, co-director of the Boand Family Foundation, ${ }^{122}$ donated $\$ 12$ million to the UW department of chemistry, ${ }^{10}$ as stated at the outset. LD and Boand were already "Presidential Laureates" for earlier outsized gifts. ${ }^{10}$ According to the sum of gift receipts obtained through public records requests, LD and Boand donated $\$ 15,234,864.00$ to the UW as of August 2017. ${ }^{123}$ Other UW announcements place the figure in excess of $\$ 22$ million (the sums in references 9 and 10). A $\$ 9$ million gift was made by Lumera, ${ }^{124}$ the company founded by LD to commercialize his technology (Figure 5). ${ }^{46}$ With this gift, Lumera joined the company of mega-philanthropists Bill Gates and Paul Allen. In 2003, there was perhaps the appearance that Lumera might become the next Microsoft. It didn't. (See Adjudications.)

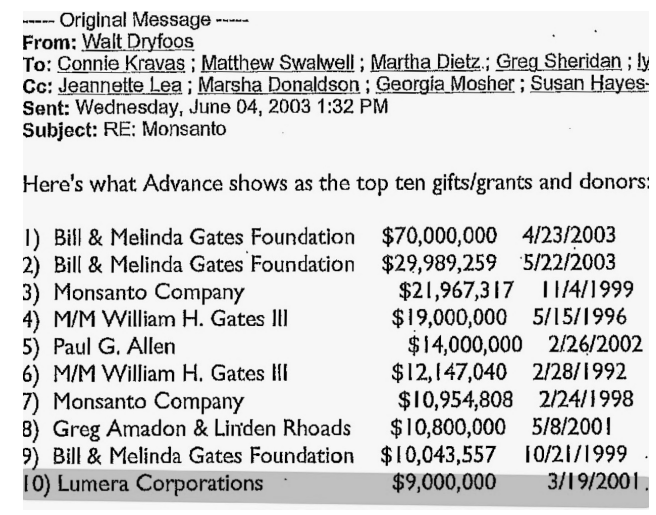

Figure 5: Top ten gifts to the UW. Email from W. Dryfoos to C. Kravas et al. 2003, Jan 4.

On June 19, 2010, BK wrote to Dean Cauce about the reason, in his view, for the failure to report results to the NSF with transparency: "The $\$ 40$ million vii [the value of LD's estate promised to the UW Department of Chemistry during an external department review meeting in 2000] tossed into a cash-poor environment was a license to commit any excess. It was a conflict of interest. There should be rules prohibiting such gifts since we rely on institutional mechanisms to check our behavior."125 Not four months later, Cauce thanked LD for donations given and anticipated: "I also appreciate your telling me that you are considering a future gift..."126 (Figure 6).

The retracted 1967 paper $^{4,6}$ was submitted from Michigan
State University (MSU), where LD was awarded B.S. and M.S. degrees, as well as from Harvard University where LD earned his Ph.D. degree. In 2000, LD was named a distinguished alumnus of MSU, despite the fact that words, pictures, and numerical data from Zhitnikov and Kolesnikov ${ }^{5}$ had appeared in a retracted publication submitted in MSU's name. ${ }^{4}$ According to MSU records, LD and Boand made donations exceeding several million dollars to the MSU College of Natural Sciences. ${ }^{127,128,129,130,131}$

Almost everyone discussed herein was advantaged in one way or another by LD's personal and professional fortunes. Dean Cauce secured large donations for her school and was subsequently promoted to Provost and then to President. Hopkins oversaw LD's dramatic boost to the grants and contracts income of his department; ${ }^{132}$ he anticipated receiving the bulk of [the LD-Boand] estate, "expected to be ca. $\$ 30,000,000^{\prime \prime 133}$ (Figure 7), up from $\$ 20,000,000$ in 2002. ${ }^{134}$ Kwiram had endowments named in his honor. ${ }^{9}$ Six faculty members earned chairs or professorships endowed by LD and his wife (Figure 13, below). Reid became LD's successor as NSF center director during the term of its \$18 million renewal (2007-2013), a prestigious position that came with the control of a large research fund. Any chemistry faculty member could hope to win "free" postdoctoral scientists, as the \$12 million-donation from LD in 2017 was earmarked for postdoctoral support. ${ }^{9}$

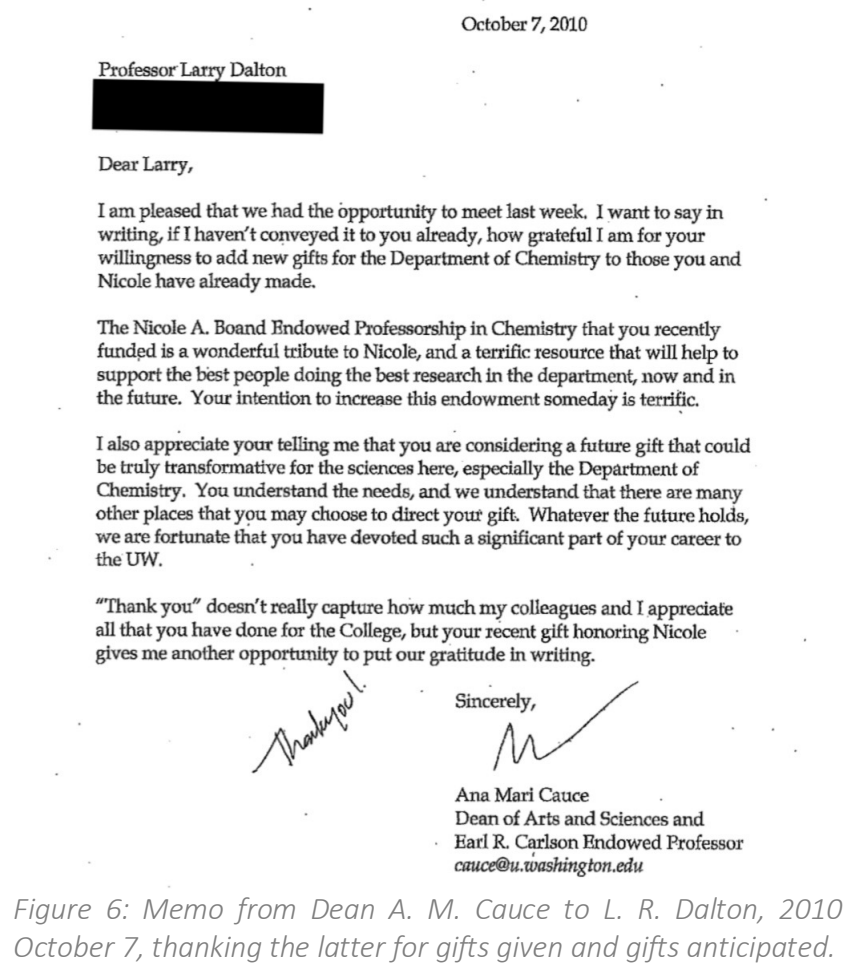

October 7 , thanking the latter for gifts given and gifts anticipated. 


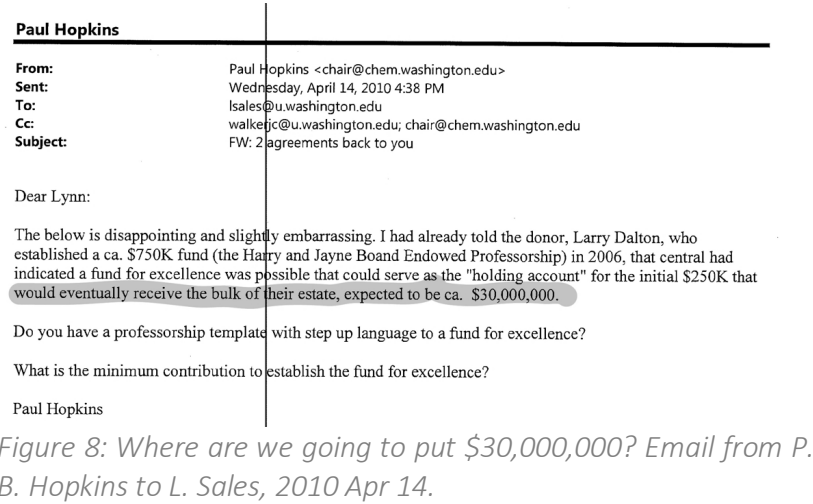

Apart from being named the Larry R. Dalton Professor of Chemistry, Robinson received a large distribution of stock from Lumera, as shown in the liquidation flow chart in Figure 8 . The UW received 493,793 shares, and Robinson received 61,724 by an agreement that was recorded before the UW became involved. ${ }^{135}$ Lumera stock was selling for $c a$. $\$ 7$ a share in 2004. ${ }^{136}$ The UW chose to honor this transfer of wealth, even though it seemed unusual to the technology transfer department and was separate from the allocations to "inventors." 135 If a payment of this kind was tacit in 1998, then the recruitment of LD by the UW, an effort supported by Robinson, has at least the appearance of impropriety. There are reasons to question whether the hiring of LD as a professor at the UW was convolved with foreknowledge of the monetary payouts to the institution and to individuals in addition to honorary endowments.

\section{Page 4 of 5}

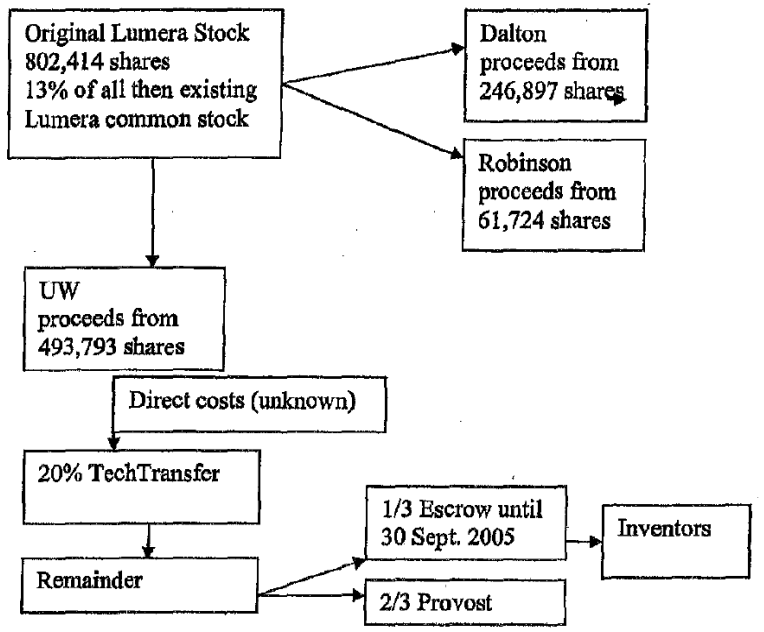

Figure 7: Flow chart of Lumera stock distribution from UW TechTransfer memo. ${ }^{135}$

\section{Records}

Facts and quotations cited herein were obtained from the open literature, the author's correspondence, as well as from lawfully obtained public records. In 2013, we requested all documents associated with UW scientific misconduct investigations in the preceding five years that included the two internal investigations of the conduct of LD authorized by Dean Ana Mari Cauce. (See Adjudications section below.) Not one page of the 174 released after a nearly year of successive delays concerned either of the UW investigations of LD. ${ }^{137}$ BK then hired a lawyer to make a more targeted and assertive public records request. After nearly another year of delays, the attorney had to insist that the UW comply with the law. In November 2016, BK received a pdf file of 2,617 pages. ${ }^{138}$ In order to see more clearly how LD's gifts affected UW decision making, BK engaged a second lawyer, who requested all records and correspondence pertaining to LD's donations to the UW. At first, the UW provided only a two-page Excel spreadsheet of dates and sums of money. ${ }^{139}$ BK filed suit ${ }^{140}$ for the associated correspondence, public records to which he was entitled, and received 3,367 more pages ${ }^{141,142}$ including 353 pages of financial transactions spanning twenty years ( $c a$. $\$ 20$ million) and the approvals and solicitations of five successive UW presidents as well as the Board of Regents. Public records were also requested from the Washington State Executive Ethics Board (WSEEB). (See Adjudications section.)

In March of 2018, the UW proposed settling our lawsuit. ${ }^{140}$ During negotiations, our first request included the adoption by the UW of an ICOI policy along the lines of Penn State (above) and Northwestern (below), both of which specifically highlight the responsibilities of administrators in the face of large gifts. The UW refused to strengthen its policies, claiming through their attorney that they already had an ICOI policy and would make no amendments. The policy that they cited does not mention "institutional conflicts," or "donation," or "senior administrator." 143,viii Resnik, who surveyed the ethics policies of the top 100 American universities in 2016, did not consider the UW to be one of the institutions with an ICOI policy. ${ }^{17,144}$ The UW settled BK's lawsuit in June of 2018.

The records cited herein, not available otherwise, will be provided as a supplementary pdf file downloadable from the journal website. We are respecting the anonymity of one correspondent at his request. All of the public record releases are available to anyone upon request (bart.kahr@nyu.edu).

Documentary evidence is also essential because we are all subject to bias, and we are much more psychologically adapted to seeing the bias in others than in 
ourselves. ${ }^{145,146}$ Therefore, we have relied exclusively on written records in this account. Throughout our experience, so as to guard against bias, we continually asked UW representatives to explain themselves. In June of 2010, BK wrote to Dean Cauce:

I am fascinated by your statement that "The issues do appear to be complicated and yours is only one perspective on the issue." If there is another perspective, I would be eager to hear it. I am surprised that you found such a perspective. In 7 years, no one has ever offered an explanation as to, 1. why my reports were suppressed, 2. why certain parties appropriated intellectual property, 3 . why I was told to stop asking questions... If there are reasonable answers, I would love to hear them. Perhaps my concerns stem from nothing more than a failure of my imagination. If I heard the other perspective that justifies these actions, my concerns might melt away... ${ }^{147}$

She did not reply.

To be fair, we repeatedly asked UW representatives to fix any early mistakes in judgment that might have changed as new facts came into view. For example, in 2015, BK admonished Dean Stacey: "Admit when you are wrong. Fix your mistakes. Act like human beings. Act like academics at the very least. I am not going to sue you"148 (emphasis removed).

Stacey did not reply. BK did sue the UW, but only for public records.

\section{Adjudications}

\section{University}

Dean

The exchanges between BK and his former colleagues in 2009, copied above, eventually brought Dean Cauce into the discussion. Cauce insisted that BK make a complaint with the UW Office of Scholarly Integrity. "An allegation of scientific misconduct - a very serious offense - must be made formally using university processes," she said. ${ }^{149}$ BK, who had already moved to NYU, refused to initiate an internal investigation against a major donor. ${ }^{147}$ He said he did not trust the UW. Cauce replied, "When you question the university, you are questioning my personal integrity... We have all been quite clear with you about what to do next. The ball is in your court."149 BK was not then questioning Dean Cauce's personal integrity, nor was he persuaded by her exhortation. He said precisely this:

I am not interested in filing a misconduct claim through the University. This is because I don't trust the University to pursue such claims (I say this with all due respect to you and Anne [Ackenhusen, see below]). I am wholly convinced, through my experience, that it is virtually impossible for those with small grants at the UW to challenge those with large grants. ${ }^{125}$
David didn't take on Goliath with just a slingshot (emails and suppressed reports in my case). He believed he had God on his side. If I am going to formally take on [LD et al.]...I want to be certain that I have God, or someone with comparable authority, on my side. ${ }^{147}$... If I authorize an investigation, I am encouraging you to use a cudgel. You can beat the accused, which does nothing for me, or you can exonerate them, which is in effect using the cudgel on me.

BK asked Dean Cauce not to beat him for doing his job, i.e., to insist on honest reporting in science. She ignored his pleas, and in July 2010, initiated two investigations, one executed by the Office of Scholarly Integrity (OSI) ${ }^{150}$ and the other by Cauce's Office of the Dean, ${ }^{151}$ despite being advised by BK that such investigations would be burdened with ICOIs.

Public records show that Cauce immediately began to consult with others as to how she should handle an inquiry that she was asked not to initiate by the complainant. The UW Divisional Dean of Science, Werner Stuetzle, advised her to "avoid ANYTHING that even remotely suggests a cover up." ${ }^{152}$ Meanwhile Cauce, Stuetzle, Hopkins, and Stacey, as well as many others, were in regular communication with their legal team, the Office of the Attorney General of Washington State, according to over 100 email messages with content redacted under attorney-client privilege (Figure 9). They set up frequent meetings, as, for example, the following gathering organized by Stacey with Stuetzle: "I've asked Clark Shores, Assistant AG, to brief me on the allegations that have been made over the past several years pertaining to [sic, arising from] a former faculty member in the Chemistry Department...l'd like to have you at this meeting...Paul Hopkins will also be there. The meeting will be covered by Attorney-Client Privilege." ${ }^{153}$ We did not know that our inquiries had engendered so much legal firepower. ${ }^{154}$ We had no legal advice until 2016, when we began collecting public records.

The internal UW investigations both exonerated LD of any abuses of RCR standards, ${ }^{150,151}$ including transgressions that he subsequently admitted. ${ }^{97}$ The work products of these

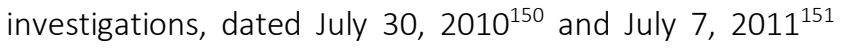
bracket Dean Cauce's October 7, 2010 solicitation for additional gifts from LD shown in Figure 5 .

In her investigation, Dean Cauce justified the decision to suppress BK's results to the NSF: "[The Principal Investigators were] making this decision [not to include your data] in preparing a second-year annual report in a five-year project, where it is common not to include details of preliminary findings. We believe that [the exclusion of your report] was within professional norms."151 In our experience, this is not and has never been normal in science. 

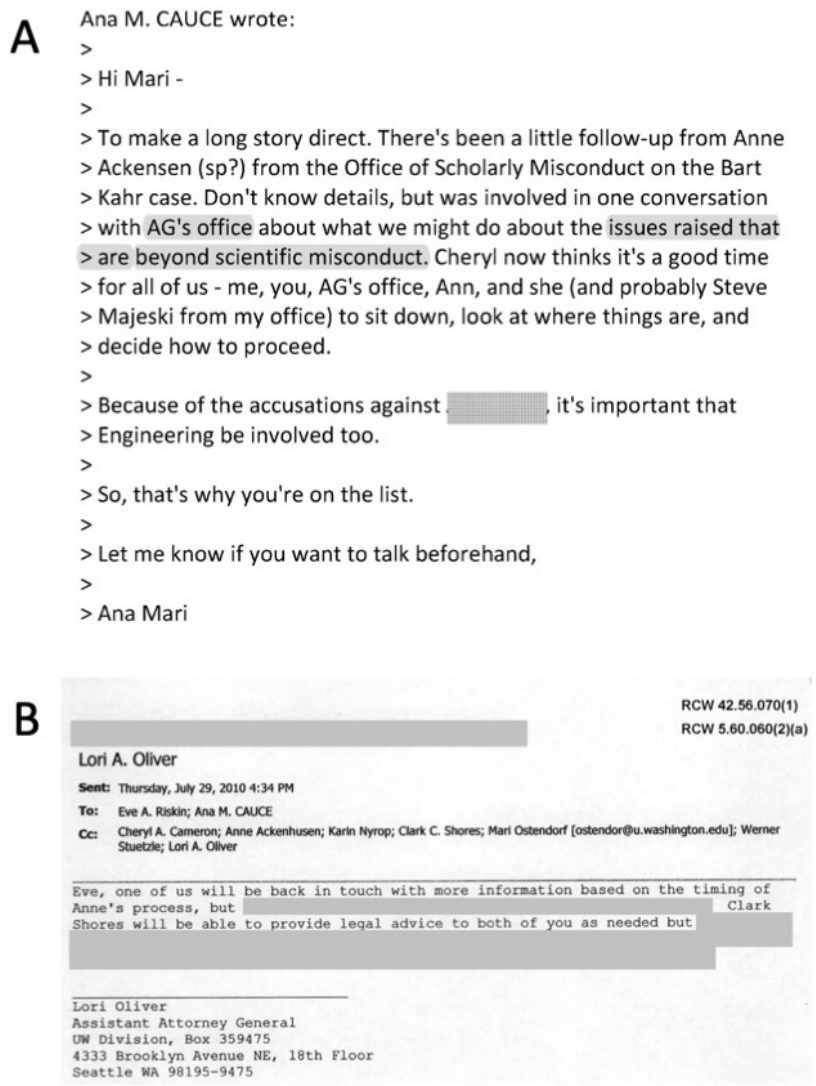

Figure 9: Examples of messages about and with the Office of the Attorney General of Washington. (A) Message from Dean Ana Mari Cauce to Mari Ostendorf (currently Associate Vice Provost). This message was on or before 2010 July 29. We wonder what Dean Cauce means by "issues raised that are beyond scientific misconduct." (B) Lori Oliver, Assistant Attorney General, to Eve Riskin (currently Associate Dean of Engineering) and Dean Cauce.

Later, Cauce told BK that his NSF 2004 report was not suppressed because it was cited by Robinson in 2011, seven years later. ${ }^{151}$ BK replied:

Yes, I made them include that citation in 2009 [sic]! !ix The report was successfully suppressed when it mattered, during the renewal of the STC grant ca. 2006-07. The report was not suppressed forever, as I made sure, but it was suppressed for a very long time. What happened in 2009 doesn't count because by then all money had been long awarded.

Having been corrected, Cauce repeated the same falsehood in 2012 to Nature reporter Eugenie Reich, while reiterating her idea of what is required in science reporting: "There is no dispute in this instance about a grant application or a grant renewal. The dispute here is about what should be included in an annual progress report to NSF." 155 However, as BK explained to Dean Cauce in 2010, the dispute was squarely centered on whether the NSF was properly informed about major problems in the years before the UW asked for a second allotment of $\$ 18$ million in 2007. "You showed this letter to Paul Hopkins and he approved it?" said BK. "He obviously knows that at issue is what was withheld from the NSF BEFORE the grant renewal."156

According to the NSF, "Project reports are a critical communication between you and the program(s) that manages your award. [They] inform Program Officers about your progress, successes achieved, discoveries made, as well as impediments that you have encountered and your plans for overcoming impediments" ${ }^{77}$ An expert's formal report stating that the science at the heart of a federally funded science center is wrong surely qualifies as an "impediment" that, according to NSF guidelines, ought to be addressed immediately. The specific reporting guidelines for the NSF's 2005 Science and Technology Center awardees say this: "Discuss any problems you have encountered in making progress toward the Center's research goals/objectives during the reporting period as well as any problems anticipated in the next period. Include your plans for addressing these problems." ${ }^{157}$ In the UW Center's 2006 report, we find the following: "1C. PROBLEMS ENCOUNTERED DURING REPORTING PERIOD. No significant problems have been encountered during this reporting period." ${ }^{158}$ As outlined in section subsection "2004", huge problems were encountered.

The enumerated list below indicates to us that Dean Cauce did not consider all of the evidence available, was unwilling to revisit her obvious errors in fact and/or judgment, and/or was burdened by ICOIs.

1. Cauce did not reckon with correspondence in her possession, such as Reid's judgment that "it was clear to all of us...since 2004 [that the science was something other than being reported],"103 Kwiram's suggestion to "moderate our importuning," 72 or Jang's accusations of LD. ${ }^{86}$

2. Cauce's interpretation of BK's report was upside-down because she misunderstood it. ${ }^{151}$ The report said that "considerable refinement" is needed. ${ }^{75}$ Cauce interpreted that phrase as BK's criticism of his own conclusions. BK replied: "You criticize my report because I stated that 'considerable refinement' is needed. But, not of my work, as you presume. Of their assumptions. The phrase is taken from my following sentence, 'we have shown that the model for EO [electro-optic] activity in polymers resulting from dye reorientation needs considerable refinement.' If you don't understand what you are reading, please don't pass judgment."156 Cauce was shown to be confused, but she did not revise her position in response.

3. As for the disputed paper, ${ }^{7}$ Cauce wrote to BK, "Measurements rely on the availability of the TCP [dyes] that you co-invented, but the emphasis of this paper is not the invention of the TCP chromophores." That is true, but it does not matter in science, because of the priority rule, 
"which accord[s] all credit, and so all the personal benefits that go along with credit," to the first to demonstrate by publication "a particular fact or procedure, and none to other programs pursuing the same goal."159 The purpose of publication is so clear to every academic that it should not require a supporting citation. If you publish a paper about something that did not exist before and you give no indication as to where it came from, you are claiming an invention. Publication establishes inventorship. That is why public disclosures can vitiate patents. ${ }^{160}$ Only the ninth publication about TCP chromophores, written by Jang, ${ }^{x}$ includes BK as a coauthor. ${ }^{161}$

4. Cauce questioned LD only about the 2004 paper in Inorganica Chimica Acta. $^{7}$ It is unlikely that her staff searched LD's contemporaneous papers during her investigation, because she would have found others coauthored by LD and Jen that clearly claim inventorshipe.g. ${ }^{94}$ published in August 2005, at least six months after Jang's charges of ethics violations. The heading of Section 4 of reference 94 is "DEVELOPMENT OF...CHROMOPHORES BASED ON PYRROLINE ACCEPTORS." It contains 1003 words and zero citations, implying that what is described is original. The title of the patent shared by Jen, Jang, and BK, issued in 2007, is "Pyrroline chromophores." ${ }^{85}$ The paper and patent are on the same subject. There is no question that Jen knew the origin of this invention; ${ }^{97}$ he shared a patent application with BK. LD knew too. Jang had already told him in no uncertain terms: "Professor Kahr is a coinventor." 86 LD could have repaired the August 2005 paper, ${ }^{86}$ but he elected not to do so.

5. LD's retracted ${ }^{8} 2004$ paper $^{7}$ had already been marked in the published record as an abuse of the work of others at the California Institute of Technology ${ }^{162}$ before Cauce even considered it as an abuse of BK's work. This would have been revealed to her had she tried to download reference 7 from Google Scholar.

6. During an inquiry into whether LD published the work of others without consent, 7 Cauce calls LD "gracious," "graceful," and having a "generosity of spirit," while his efforts were, "GREATLY appreciated"163 -- in the space of 105 words (Figure 10). She then declared his innocence. ${ }^{151, \mathrm{xi}}$ LD's publication? ${ }^{7}$ was later retracted. 8,97,107

7. As Provost in 2015, Cauce announced to her faculty that one of her chief ambitions was to put "commercialization and entrepreneurship on steroids." 164 LD was a university leader in commercialization and entrepreneurship.

8. Lastly, there is the common-sense expectation of competing interests in an investigation of someone who had given tens of millions of dollars to Cauce's school and who had promised an estate of tens of millions more (Figure 6). What administrator would not worry about being the person who had jeopardized such a windfall for the university?

The Washington State Appearance of Fairness Doctrine ${ }^{165}$ "is a rule of law requiring government decision-makers to conduct non-court hearings and proceedings in a way that is fair and unbiased in both appearance and fact. It was developed by the courts as a method of insuring that due process protections, which normally apply in courtroom settings, extend to certain types of administrative decisionmaking hearings... By following Appearance of Fairness requirements, local governments have a method for disqualifying decision-makers from quasi-judicial hearings who have prejudged the issues, who have a bias in favor of one side in the proceeding, who have a conflict of interest, or who cannot otherwise be impartial."166 According to the UW Research Misconduct Policy, a COI exists "when a person participating in the research misconduct proceeding has a substantial connection or interest related to the complainant or respondent that might bias or otherwise threaten the integrity of the proceeding. This includes, but is not limited to, personal, professional, and financial conflicts of interest." 167 According to our reading of the Washington State Appearance of Fairness Doctrine, and the UW Research Misconduct Policy, Cauce should have recused herself.

\section{Office of Scholarly Integrity}

The director of the UW Office of Scholarly Integrity (OSI), Anne Ackenhusen, conducted the other investigation initiated by Dean Cauce. Ackenhusen's investigation was coordinated with Cauce's from the beginning, as indicated in Ackenhusen's hand-written note: "met with Ana Mari [Cauce]... developed analysis." 168 Nevertheless, the UW often characterizes these investigations as "independent." 112

Ackenhusen also eschews documentary evidence, while displaying an ignorance of the scientific method. She wrote to $\mathrm{BK}$ in her investigation report, "[Y] our theory that the dye molecules, in essence, were not aligned had not really been tested. You indicate that, while you believed that the orientations reported for these dyes should have been discernable $[\mathrm{sic}]$ to the naked eye, you were unable to see any such orientation or detect anything with instruments in the lab."150 In other words, because the instruments in our laboratory, optimized for recording linear dichroism, failed to detect any, we did not really assay whether there was anything. In fact, the hypothesis that the dye molecules were aligned had never been tested before BK made his measurements. Ackenhusen turns on its head the concept of the null hypothesis, ${ }^{169}$ the assumption central to empirical science that two things are not correlated unless proven otherwise. Rather than establishing that electrooptic activity and dye orientation were correlated 
A From: Ana M. CAUCE

Sent: Thursday, September 09, 2010 1:04 PM

Subject: RE: Kahr Authorship Claim

Dear

Take your time to consult before you make the decision about authorship.

There is NO rush on this. We're hoping we'll be able to give a final response to Professor Kahr sometime in late October

I really do appreciate your willingness to look into this, and your generosity of spirit (regardless of the final decision about authorship.

All my best wishes toward a speedy recovery

Ana Mari

Ana Mari Cauce

Dean, College of Arts and Sciences

$B>$

$>$ Thank you so much for taking the time to think this through, and for $>$ the gracious (and graceful) approach you have taken to the question. I

assume

$>$ it is ok to share your response with others.

$>$ GREATLY appreciated,

$>$ Ana Mari

$>$

Ana Mari Cauce

$>$ Dean, College of Arts and Sciences

Figure 10: Emails from A. M. Cauce to L. R. Dalton, 2010 September 9, during a scientific misconduct inquiry. Cauce asks Dalton whether he published a paper ${ }^{7}$ about something he did not invent in the same journal in which he had previously reported the results of "ENP. ${ }^{6}$ Dalton later conceded that he did publish misappropriated research in 2004, but he blamed his students. ${ }^{97}$

phenomena, UW researchers had simply assumed that electro-optic activity was evidence of dye orientation.

The OSI and Cauce took the position that BK and LD merely had an honest difference of scientific opinion. ${ }^{150,151}$ According to NSF regulations, "[r]esearch misconduct does not include honest error or differences of opinion." ${ }^{\prime 170}$ Ackenhusen wrote, "It is UWOSI's conclusion that there was a difference in scientific opinion between you and Jen... Apparently, in 2003-04, Jen (and, according to you, Dalton) continued to believe that there was a high degree of dye orientation, and thus chose not to report your alternate theory to NSF." For a second time, she characterizes the observations made in BK's laboratory as a "theory." BK replied, "This is Science. Who cares what they believed? There is only one way to directly measure dye orientation. I made it. They didn't...". ${ }^{171}$ In fact, the Jen laboratory was very concerned, internally, about the question of dye orientation as soon as Jang began to work there. ${ }^{172}$

Even earlier, in 1999, LD, Robinson, Jen, and coauthors admitted that they had not measured dye alignment directly and that caution should be exercised when interpreting the electro-optic measurements that they had made in terms of their theory of dye orientation: "Agreement between theory and experiment is a necessary but not sufficient condition for the correctness of a theory." They went on to say, "The quantitative agreement should not be overly interpreted as there is some adjustability to parameters such as chromophore shape, applied electric field strength, dielectric constant, etc." ${ }^{54}$ Linear dichroism had been established long before as one of the few direct methods for measuring dye alignment in electrooptic materials. ${ }^{68}$

In our view, there are major problems with Ackenhusen's position of an honest difference of opinion that she did not consider: 1) An honest difference of opinion can only be held by honest parties; 2) There cannot be disagreement about something any scientist could see with the unaided eye and a computer monitor, as explained in detail to her; ${ }^{171} 3$ ) Reid admits concordance, not a difference of opinion; ${ }^{103}$ 4) Ackenhusen never asked BK about the limits of detection of his instruments; 5) Lastly, few if any living persons have ever considered the orientation of more dye molecules in more different things than BK. $58,173,174,175,176$

RetractionWatch.com, the prime mover in this decade in defining and reforming deviations from accepted practice in science, has called for original documents supporting university science misconduct investigations because secrecy is systemic. ${ }^{177}$ As they reported, ${ }^{178}$ Richard Smith, the former editor in chief of the British Medical Journal, believes "[investigation reports] should surely all be published: justice must not only be done it must be seen to be done... We need to achieve a world where universities can have no confidence that reports will remain buried." The two UW investigation reports and BK's unsolicited replies are therefore included in the Appendix. In addition, a number of hand-written notes by Ackenhusen are included in the public records files, which provide a window into the thought processes of the investigators. One of these is reproduced in Figure 11; here, Ackenhusen opines that whatever BK did regarding the TCP chromophores, it was quite like imagining an "electric bicycle" but not daring to build one. ${ }^{179}$ According to the Manual of Patent Examining Procedures, "The definition for inventorship can be simply stated: 'The threshold question in determining inventorship is who conceived the invention. Unless a person contributes to the conception of the invention, he is not an inventor. ... Insofar as defining an inventor is concerned, reduction to practice, per se, is irrelevant."'180 


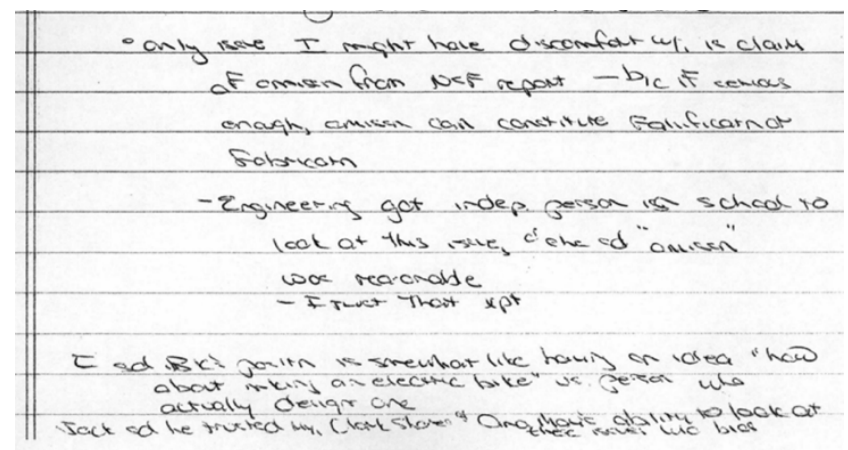

Figure 11: Fragment of a page of written notes by Director of the Office of Scholarly Integrity, Anne Ackenhusen: "only issue I might have discomfort $w /$ is claim of omission from NSF report - b/c if serious enough, omission can constitute falsification or fabrication. Engineering got indep. person in school to look at this issue. [Illegible] "omission" was reasonable - I trust that xpt. I said BK's position is somewhat like having an idea "how about making an electric bike" vs. person who actually designed one. Jack [Johnson, Young's chief of staff] said he trusted my, Clark Shores [UW counsel] \& Ana Mari's [Cauce's] ability to look at these issues w/o bias."

\section{President and Provost}

In 2012, after the catastrophe at PSU that led to the ouster of its President, Graham Spanier, ${ }^{32}$ the UW President, Michael Young, sent an email to his community entitled "Restoring our Pledge of Integrity." Young wrote, "[T]he news of the past year left us with far too many examples of the lasting harm done by malicious individuals, whose acts were extended by the inaction of those who might have spoken up. Persons entrusted with academic, administrative, and athletic responsibilities at institutions of higher education have been found to have actively betrayed that trust - or to have stood by passively allowing the destructive behavior to continue."181

Buoyed by this apparent commitment to academic values at the highest level, BK asked Young to reconsider investigations of a donor by his subordinates burdened with IFCOIs. BK sent to Young copies of correspondence relating to LD by express mail. Young had solicited information of this kind from every quarter of the university. He then exchanged emails with his Provost, Cauce (Figure 12; 2012, Jan 18) saying that he had no intention of looking at BK's mailing but would wait to send his reply until it arrived so as to not appear disinterested. Cauce approved of this ruse ("Your instincts are perfect!") and encouraged Young's delay so BK would not have "a reason to think you didn't take it seriously." (Figure 12)

MDH also appealed to Young in 2012, advising him that:

Kahr's results were not 'details of preliminary findings,' as then Dean Ana Mari Cauce described them... And by no means was it 'within professional norms' to excise them from the annual report to the NSF, as she claims... 'Professional norms' dictate that the standard for inclusion or non-inclusion of a particular result would be that, at a minimum, if the result would have a material outcome on the renewal proposal, it must be included; [...] Anyone who knows the first thing about the optics of materials will tell you that if Profs. Dalton and Jen had told the NSF of Prof. Kahr's demonstration that the polymerembedded dyes were not actually aligned in the electric $A$ > On Jan 18, 2012, at 4:04 PM, "Michael K. Young" <michael.young@uw.edu> wrote: > I'm not actually intending to redo all this..., and chemistry was never my strong suit in any event. Just thought it is a courtesy to delay our reply until he's had time to send his materials....

$>$ $\gg$ Cheers.

$>>$

$>$ Mike

B On Jan 18, 2012, at 4:06 PM, "Ana M. CAUCE" <cauce@u.washington.edu> wrote:

> Sorry, I was teasing you! I'm taking a redeye tonight and thought it might be just the right thing to make sure I slept on the flight.

$>$

$>$ Your instincts are perfect! Don't want to give him a reason to think you didn't take it seriously

$>$

$>$ Sent from my iPad

Figure 12: Email from President M. K. Young to Provost A. M. Cauce (A) and reply from Cauce to Young (B). Young's chief of staff, Jack Johnson, replied to BK on the president's behalf, "This office has reviewed the correspondence on this matter and conferred with those who conducted the earlier examinations of your allegations." (Johnson JG. Letter to Kahr B. 2012 January 26, see appendix) But, consistent with (A), Johnson drafted Young's response before the correspondence arrived, as shown by an additional message from Young: "Jack and Ana Mari, This looks like a perfect response. But let's wait until he has sent the material he promises in his email. Thanks, Mike." (Young MK. Email to Johnson J and Cauce AM. 2012 January 18, see Appendix) 
field of the device, the STC's funding may have been jeopardized. ${ }^{61}$

Young's chief of staff wrote a letter to MDH affirming the objectivity of the UW's judgments. Young reviewed the letter and replied, "It is more polite than he [MDH] deserves." 182

Later in 2012, upon receiving a tip that LD had published "ENP" in Inorganica Chimica Acta, ${ }^{6}$ BK informed chemistry Chair Hopkins, Provost Cauce, and President Young by email of a history that should have prompted reconsiderations of past judgments by the university: "Dear Friends, I have tried to help you people, but you will have none of it. I send to you evidence [the 1967 retraction notice] that you have been defending, quite imperfectly, someone with a 45-year history of falsifying science." ${ }^{11}$ There was no reply.

The next year, Provost Cauce thanked LD for five endowed professorships (Figure 13). Such documents challenge us to find a clearer illustration of the concept of ICOIs at a university (outside of an athletics department). According to Sheldon Krimsky, who has written extensively on COIs in the academy, "No one doubts that the president, board of trustees, and the provost are sufficiently high enough in the chain of command to fall under ICOI guidelines." 183 In 2015, Cauce became the President of the UW, while Young moved on to lead Texas A\&M. ${ }^{\mathrm{xi}}$

The UW Office of Research states "Conflicts of interest in research are present when Significant Financial Interests directly affect, or could appear to affect, the professional judgment of a researcher when designing, conducting, or reporting research"184 (researcher emphasized). In evaluating the actions of the UW administration in the face

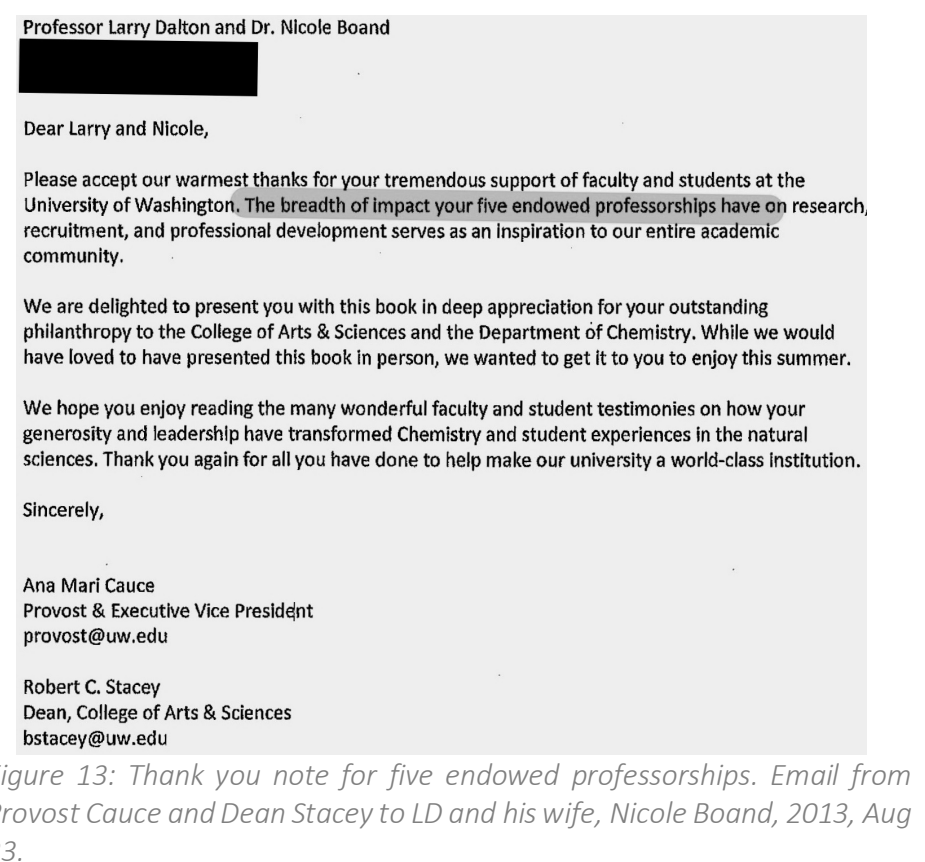

of LD's multimillion-dollar gifts, we are guided by the average person standard, a sum of money that would induce an average person to behave with bias. Shamoo and Resnik ask of the average person, "how much money does it take to influence reasoning, judgment, motivation or behavior - \$10,000, \$1,000, \$500?"185 Analogously, we propose an average institution standard, a sum of money that would induce an average organization's representatives to behave with bias. As with the average person standard, one can imagine that this sum would vary from institution to institution, depending on size and financial health, as well as on the reward system for securing donations.

Northwestern University, for example, defines a compromising sum of money from an individual in its Institutional Conflict of Interest Policy.

(1) Gifts to the University of $\$ 100,000$ or greater from any entity, whether for-profit or not-for-profit, or from any person (either per gift or in the aggregate). (2) Payments to the University for, or resulting from the conduct of, research at or under the auspices of the University which exceed $\$ 100,000$ (either per transaction or in the aggregate). Payments include income from sponsored research projects and royalties from the licensing of intellectual property when such payments may be affected by the research. (3) Equity, ownership or financial interests held by the University in for-profit entities, including equity and ownership interest resulting from the transfer of University technology where such interests have: a) a value in excess of $\$ 100,000$ in the case of a publicly-traded entity; or b) a value of any amount in the case of a non-publicly traded entity. ${ }^{186}$

If our story were centered at Northwestern University, rather than in the Pacific Northwest, would all sections of this policy have been violated? Whereas Northwestern has specified $\$ 100,000$ as an institutionally-corrupting sum, ${ }^{186}$ the UW received gifts from LD more than 200 times this limit.

\section{State}

The Washington State Ethics in Public Service Act, 42.52 RCW (12) says, "No state officer or state employee may have an interest, financial or otherwise, direct or indirect, or engage in a business or transaction or professional activity, or incur an obligation of any nature, that is in conflict with the proper discharge of... official duties"187 (emphasis added). Yet, gigantic gifts were annually solicited and accepted from a faculty member with a concerning history spanning generations. $6,8,76,97,107$

The Washington State Executive Ethics Board $(\text { WSEEB })^{188}$ is the body officially responsible for enforcing the state ethics law. According to their website, the 
WSEEB, "has jurisdiction over statewide elected officials and state employees in the executive branch; including boards and commissions and institutions of higher education." 189 BK referred the conduct of Cauce and Young to the WSEEB. The WSEEB director reported:

[T] he Executive Ethics Board found No Reasonable Cause that Ana Marie Cauce, Provost and Michael Young, President, had violated the Ethics in Public Service Act when they conducted an investigation into the alleged wrong doing [of a professor who] was a financial contributor. ${ }^{190}$

There is evidence to show that Ana Mari Cauce and Anne Ackenhusen conducted a thorough, complete, and unbiased investigation into the allegations made by Dr. Kahr in good faith and that their findings were not influence [sic] by any interest financial or otherwise, but only to reach the proper assessments of that [sic] facts. ${ }^{191}$

There is evidence to show that Mr. Young was confident in the objectivity and judgment of the persons who reached the final conclusions and did not believe there was sufficient reason to reopen the inquiry. ${ }^{191}$

The suggestion here is that there is evidence that would demonstrate that the decisions of parties representing an organization having received large sums of money and expecting to receive larger sums still were in no way influenced by this money. What evidence could this be? States write probity laws because prejudicial conduct can be unconscious and usually does not produce evidence. The American Association of University Professors makes plain that COl's must be avoided, even in the absence of wrongdoing: "Identifying a conflict of interest does not entail an accusation of wrongdoing. Conflicts of interest have been shown to affect judgments unconsciously, so a conflict of interest refers to a factual circumstance wherein an impartial observer might reasonably infer that a conflict is present." 192

We discovered ${ }^{138}$ that the alleged evidence of impartiality of the UW administration is a pair of letters, one from the UW internal auditor Richard Cordova and the other from Young. Young's chief of staff urged Cordova to craft an "over-arching institutional response - perhaps from the AG's Office... or the chair of the Regents"193 to BK's concerns about ICOIs. Cordova wrote:

I would strongly discourage the Ethics Board from [saying] that donations to the UW by a faculty member serve to create a conflict of interest that disqualifies University officials from handling matters involving that faculty member. Donations to the [UW] do not create a financial or other personal interest for those who work for the University... It is important to recognize that a very large number of UW faculty and staff make donations to the University. In spite of this, their supervisors must continue to be able to supervise them. And when complaints are made regarding those employees, those University officials cannot be obligated to either ignore the complaints or "contract out" the job of responding to them. ${ }^{194}$

Cordova's term, "contract out," is more commonly recuse. Recusal is the well-established course of action for avoiding COIs and ICOIs: "In cases of institutional conflict involving university officials or trustees... the review group [recommends] recusing the official from... decision making."24 "Under all circumstances," wrote Friedman, "actual conflict situations, as well as the appearance of conflict, should be avoided." 22 According to researchers, "the perception of a causal connection between funding and outcome is sufficient to 'prove'" ICOIs. ${ }^{195}$ Nevertheless, President Young wrote:

First, donations to the UW that [name redacted] may have made in the past or that he may intend to make in the future do not translate into financial or other personal interest of either the Provost [Cauce] or myself. While it is obviously part of our official duties to seek financial contributions to the University, the Ethics Board has never found that such possible benefits to the state agency become the separate personal interests to those who manage the agency. ${ }^{196}$

To us, these are repudiations of the very idea of ICOIs. We cannot reconcile Young's statement with the contemporary scholarship on academic ethics cited extensively herein.

We have never accused Young of putting money directly in his pockets. Nevertheless, the ICOI concept makes it clear that there are other ways to be enriched by accepting a donor's money on behalf of his institution. High-level academic administrators are evaluated on the basis of their fund-raising acumen. Would Young have been offered a third major university presidency (at Texas A\&M, after the UW and the University of Utah) if he had not been a good fundraiser? ${ }^{197}$ Would Cauce have been promoted from UW Dean, to Provost, and then to President if she had not been a good fundraiser? ${ }^{198, x i i}$ Needless to say, but said nevertheless by Deloitte, "Fundraising is essential from a president's first day in office....and only grows in importance over time in the position... There is increasing pressure on presidents to look for quick wins. As a result, many are looking for the proverbial low-hanging fruit on their campuses where they can show fast results, not only for their own boards but also for search committees for their next job."199

In 2002, the Washington State Court of Appeals advised that the "plain language" of the ethics act does not limit its application to mere individual COIs. "The express purpose of the act was to ensure that government officials conducted business in a 'manner that advances the public's interest.'...RCW 42.23.0701 creates a valid public policy in favor of prohibiting municipal officers from granting special privileges or exemption to others." 200 
As indicated above, the UW sought legal advice from the UW Division of the Attorney General's Office (Figure 9A) at the outset of their investigations. "The Attorney General's Office," according to the UW, "has been statutorily designated to provide legal advice to the University and to initiate or defend lawsuits on behalf of the University"201 even though the WSEEB is "funded and supported through the Attorney General's Office." 202 Thus, when we naïvely asked the WSEEB to review UW ICOIs, we were unaware that the Attorney General was both giving legal advice to the UW and funding the WSEEB, itself an ICOI. According to Robertson, a funder can create "a dependency which causes a decision maker to alter his or her behavior in a way that biases an outcome." ${ }^{\prime 23}$ At every turn, we find COls nested one inside the other.

The current Washington State Attorney General, Bob Ferguson, nevertheless has a clear understanding of COls. On Nov. 8, 2018, he wrote a letter to acting United States Attorney General, Matthew Whitaker, urging him to recuse himself from matters involving Robert Mueller's investigation. "Because a reasonable person could question your impartiality in the matter," wrote Ferguson, "your recusal is necessary to maintain public trust in the integrity of the investigation and to protect the essential and longstanding independence of the Department you have been chosen to lead." 204

On July 21, 2011, BK wrote to Dean Cauce:

I am surprised that you have the confidence to exercise your opinion on the matters in question [involving LD], that you did not recuse yourself as judge and jury straightaway. I expressed this concern last year... Can you hold my interests in focus when you work for an organization that has been the recipient of outsized gifts by the accused? Be sure, I am not asserting that your opinion has been compromised. I don't know that obviously. I am saying that no critical third party would presume that your interests would be pure under the circumstances. That is the essence of the principle of competition of interests. Merely because the outcome of your investigation might be compromised, the authority of your report crumbles. Credible modern organizations abide by the constraints of conflicted interests and even institute safeguards so as not to find themselves in such untenable circumstances. ${ }^{156}$

Recusal is the only recourse when you have competing interests, according to the Washington State Attorney General, Bob Ferguson. However, the Attorney General's Office, having advised Dean Cauce extensively, did not convince her, if even they tried, that she had competing interests in her official activities, which involved soliciting donations from LD at the same time that she was opining on whether he had adhered to RCR standards.

\section{Federal Agency}

If a university is unable to manage its own ICOIs, presumably external authorities at the state or federal level have the capacity to intervene. The WSEEB did not exercise this capacity, instead apparently relying on reports by UW officials burdened with ICOIs, while carrying potential conflicts as employees of UW's legal counsel, the Office of the Attorney General. The NSF Office of the Inspector General (OIG) likewise appears to us to have sidestepped all matters involving LD and the UW.

As recounted above, in subsection "2009," after LD's center had won \$36 million from the NSF, and no more support for the center would be forthcoming, the leading scientists claimed for themselves the judgments that were contained in BK's suppressed report to the $\mathrm{NSF}^{75}$ and Benedict's Ph.D. dissertation. ${ }^{78}$ The last lines of a paper by Dalton, Jen, Robinson, Reid, and others state, "the poling field-induced acentric order in the material is much lower than anticipated from previous estimates..." ${ }^{104}$ BK thus reported a variety of RCR violations to the NSF, including but not limited to the fact that $L D$, as principal investigator of a major NSF center, did not report critical -- both essential and unfavorable -- results. ${ }^{205}$ The NSF's definition of falsification is "omitting data or results such that the research is not accurately represented," which, in our view, describes this circumstance with precision. ${ }^{170}$

The NSF apparently conducted an investigation (case number A11010003). ${ }^{206}$ However, neither BK nor the scientist he identified as the chief witness, his former student Benedict, were ever contacted. After two years, the NSF OIG issued a 400-word anonymized "closeout memorandum," 206 which asserted that none of the actions described had risen to the level of misconduct. BK had earlier urged the NSF OIG investigator, Kenneth Busch, to ignore UW investigations and communications, compromised by huge gifts from LD. The closeout memo stated, "Improper investigation of allegations by a grantee... is not an issue... that our office would investigate." ${ }^{206}$

Closeout memos are typically paired with investigation reports ${ }^{207}$ that can be obtained through the Freedom of Information Act (FOIA). ${ }^{208}$ BK made a FOIA request (no. 1324) but the NSF OIG refused to release the report or any associated documents, citing exemptions ${ }^{\text {xiii }}$ including "predecisional agency records" or "records the disclosure of which would constitute an unwarranted invasion of personal privacy." ${ }^{\prime 209}$ BK appealed twice, requesting redacted documents because the FOIA "mandates that any 'reasonably segregable portion' of a record must be disclosed... after the redaction... of the parts which are exempt." ${ }^{\prime 10}$ BK insisted that if there are records that he is not privy to, redact those and release the remainder. According to the Counsel to the Inspector General, for example, "The Supreme Court has interpreted FOIA exemption (b)(5) ${ }^{\text {xii }}$ broadly, so as to protect predecisional 
information which affects the 'decision making processes of government agencies.'” (See Appendix for legal citations within the Counsel's letter.) With regard to the personal privacy exemption, the OIG Counsel said, "Disclosure is unwarranted if the private interest in nondisclosure outweighs the public interest in disclosure."211 The NSF General Counsel affirmed that the agency would withhold all records "to the extent that they exist."212

In 2016, BK's attorney requested from the UW all communications between the UW and the NSF OIG pertaining to their respective investigations. Not a single record was produced. Perhaps the NSF OIG concluded its investigation during pre-decisional agency deliberations. ${ }^{208}$ From public records releases, we read of UW officials admitting that they also had never been contacted by the OIG. Hopkins wrote, "the allegation of an nsf investigation is very interesting. i wonder if the reporter got confirmation it EXISTS? seems foolish to report it w/o such confirmation, yet UW has heard nothing of any such investigation, which i'm told would be unusual"213 (lower case in original). After the NSF investigation had been underway for 18 months Cauce wrote, "I am not aware, at this time, of any communications [the NSF OIG] had with us." 155

We cannot judge the NSF OIG's apparent inactivity and secrecy. When pressed to explain their actions, the NSF General Counsel replied: "The agency's hands are somewhat tied once the [OIG] decides - for whatever reason - not to pursue a matter involving research misconduct."214

In a public lecture at the NSF headquarters on December 15, 2014 (online ${ }^{215}$ ) BK politely explained to assembled NSF staff that they had been misinformed by the UW. However, LD and Robinson continue to receive NSF funding for their research (Award No. DMR 1303080) and have even received a special unsolicited extension of funding. ${ }^{216}$ This is surprising given the following records cited in this paper: $6,8,76,97,107$.

In the aftermath of the explosive Congressional hearings regarding the so-called Baltimore affair, ${ }^{217}$ federal science and regulatory agencies needed clearer guidelines for adjudicating scientific misconduct. The rules crafted sought to balance government oversight with the concerns of scientists and universities fearful of outside intrusion. The balance was set in favor of the latter. ${ }^{37,218}$ In 1992, the authors of an influential National Academies report on scientific integrity unanimously voted to strike the phrase "other serious deviations from accepted research practices" from NSF's definition of misconduct, which now only includes "fabrication," "falsification," and "plagiarism."219 Buzzelli of the NSF OIG courageously argued for a more expansive definition of misconduct, the preservation of the "deviations from accepted research practices" phrase, and a more aggressive federal role, but he did not carry the day $^{218}$ after fiercely contentious negotiations among stakeholders. $^{37}$

Today, a judgment from the NSF OIG seems substantial. It may not be, in general, because the agency is hamstrung. Most scientists are unaware of these limits. The Code of Federal Regulations that govern the NSF-OIG instructs that "Awardee institutions bear primary responsibility for prevention and detection of research misconduct and for the inquiry, investigation, and adjudication of alleged research misconduct. In most instances, NSF will rely on awardee institutions." 170 "[I]f an allegation is made directly to the granting agency," according to Smith, "the agency will usually refer it to the university on the premise that it is in a better position to conduct inquiries and investigations than are the federal agencies." 220

The constraints on the NSF OIG, however, may not be absolute. According to Kulynych, the NSF has "established standards for institutional investigations, and the [agency] may intervene at any point if an institution appears unable to conduct a timely, thorough, and unbiased investigation,"221 as BK had claimed in his original letter. ${ }^{205}$ (Emphasis added. See also reference 222.) With respect to the UW, the NSF was not proactive, but in our view, they should have been because experts frequently cite the extra seriousness of repeated offenses in science. Kulynych calls attention to a repeating pattern of abuse that "indicates a defendant's plain indifference to professional standards, and his or her inability to function as a competent member of her profession."221 "Sanction-assigners," said Keränen, "should consider that multiple and repeated instances of misconduct suggest a degree of awareness not necessarily present in cases of singular violations and also might be suggestive of self-promoting motives." 223 Dubois et al. wrote, "[W]rongdoing in research indicates that many investigators have offended in more than one environment; oftentimes, earlier offenses are only made public once an investigator is caught at another institutions [sic] and these offenses are publicly reported. The confidentiality or secrecy of institutional responses to wrongdoing often appears to enable further wrongdoing."224 According to Gunsalus, arguably the most experienced academic investigator of deviations from common practice, "There is no statute of limitations on scientific misconduct" (quoted in 37). No investigative body chose to reevaluate its work after learning of the "ENP" of 1967 and the Russian words, pictures, and numerical data that appeared in LD's paper. ${ }^{4,6,107}$

Our dissatisfaction with the NSF-OIG reflects a national system for adjudicating scientific misconduct that has been characterized as ineffective or worse. David Wright, upon resigning as director of the Health and Human Services Office of Research Integrity, wrote in an open letter that the 
culture of his office was "seriously flawed"..."secretive, autocratic and unaccountable."225

A former NSF inspector said in her PowerPoint presentation, while reaching out to the community of scientists, "INTEGRITY STARTS WITH YOU! If you are aware of, or suspect misconduct in science, fraud, waste [or] abuse...contact [us]."226 However, young scientists are not at the same time told, in the face of exhortations to be vigilant and proactive, that should you bring forward concerns about profitable science at a university, you may be on your own as the agency ordinarily defers to the awardee institution.

\section{Conclusion: Lessig's Institutional Corruption}

Typically, being right and telling the truth is all that is necessary to carry the day in science. How then did the dispute described herein last so long? While fifteen years seems like a long time, it is not uncommon for research projects in our laboratories to linger in one form or another for decades or more. This dispute was merely like any other difficult project. Typically, nature is the obstacle. Here, money was the obstacle. Otherwise, persistence and patience are exercised in the same way.

Moreover, fifteen years is on par for a struggle of this kind. Dr. Nancy Olivieri battled the University of Toronto for more than a decade $227,228,229$ after speaking out about the dangers of a drug for a blood disorder in children. She was disparaged by the manufacturer and the university. Meanwhile, in 1998, the university and the manufacturer were negotiating a \$20 million donation for a new biomedical science center. ${ }^{230}$ The University of Toronto, with obvious competing interests, described the drug's safety as a "complex issue" and "a scientific controversy"231 (aka "honest disagreement", a universal free pass).

In 1998, LD also made his first donation to the UW, ${ }^{139}$ the start of several tens of millions anticipated. Twenty years ago, any researcher putting that kind of money at risk could easily be reduced to a persona non grata in the eyes of the administration of a large North American public research university. Doubt is the aim if you want to vitiate credible scientific concerns. ${ }^{232,233}$

Most whistleblowers will insist that they had no choice. However, everybody has choices. Alford is perceptive here. The choiceless choice "is a formula for relief from the almost unbearable regret of having let oneself be sent on a suicide mission." 234 And, that is why so many whistleblowers are left broken, because they are "unable to assimilate the experience, unable, that is, to come to terms with what they have learned about the world." 234

At the outset, whistleblowers are often naïve, or are more particularly burdened with what behavioral scientists call naive realism, the belief that if you only have the chance to sit down with reasonable people and show them the evidence that you have accumulated, they will likewise be persuaded to adopt your point of view. ${ }^{145,146}$ Look, the color doesn't change when I rotate your sample in front of my computer monitor. Look at what they did in the past. Our expectation that academics will be moved by evidence was misguided. We did not appreciate how people typically respond when challenged.

Prosecutors, whose convictions have been shown to be wrong in light of subsequent DNA analyses, often work against the exoneration of innocents, refusing to recognize new evidence. ${ }^{235}$ Prioritizing a jury conviction over physical evidence mitigates the prosecutor's discomfort in having wrongfully sent someone to prison. This is a manifestation of Festinger's concept of cognitive dissonance, the notion that people will justify bad decisions to minimize the anguish of conduct that it at odds with their self-image. ${ }^{236}$

Lessig, in his recent Chronicle of Higher Education analysis, "How Academic Corruption Works," emphasizes that hard-working professionals who have made substantial commitments to the universities they manage are particularly susceptible to justifications that arise from cognitive dissonance associated with bad decisions. ${ }^{237}$ Lessig's article is abstracted from his 2018 book $^{238}$ about institutional corruption, a concept pursued with other scholars at the Harvard Edmond J. Safra Center for Ethics. The idea of institutional corruption was first introduced by Thompson in the context of politics. ${ }^{239,240,241}$ Lessig generalized the theory of institutional corruption and applied it to the academy and elsewhere. ${ }^{238}$

In our view, the collective actions of the UW administration described herein are not only examples of ICOIs, they match Lessig's definition of institutional corruption, "a systemic and strategic influence which is legal, or even currently ethical, that undermines the institution's effectiveness by diverting it from its purpose or weakening its ability to achieve its purpose, including, to the extent relevant to its purpose, weakening either the public's trust in that institution or the institution's trustworthiness." ${ }^{242}$

We emphasize that Lessig's corrupt institution is not filled with corrupt people, but often the opposite. Corrupt institutions can be filled with well-meaning people. Nevertheless, structural problems in the operation of the institution, for example the absence of credible ICOI policies, or the lack of an awareness of ICOIs and their consequences by senior leadership, render judgments susceptible to external influences that may serve the institution's bottom line while undermining its effectiveness and trustworthiness.

Teachout has shown that the terms "corrupt" and "corruption" were invariably applied by the framers of the U.S. Constitution to institutions as opposed to individuals. 
Adams, Madison, and Jefferson were not principally concerned with quid pro quo exchanges per se, but they feared that gifts would corrode the trust of the citizenry in the institutions whose members have been subject to emoluments. The appearance of impropriety is enough to corrupt an institution and divert it from its purpose, even among "ethically engaged professionals." 243

Lessig writes, "[l]t's not the bad person who's most vulnerable to corruption influences... It's the good person. The thief knows he's a thief. But the good person doesn't." 237 He continues, in characterizing the work of Ariely, et al. ${ }^{244}$ on the so-called moral-license bias:

Doing good can make you bad. Put differently, the more morally you behave, the more likely you are to cut yourself some slack... We all hew close to what we know is good and steer as far as we can from what we know is bad. But when we've behaved well, we feel entitled to deviate. Academics are usually people who have chosen to do what they do not for the money but for the freedom, or the intellectual engagement, or the desire to teach. All of these motives seem far from the motives that guide the corrupt. And yet, in an obvious, psychological way, the academic is the most vulnerable. Not only is he less likely to be experienced in the influence game, but he is also psychologically primed to be the most vulnerable. ${ }^{237}$

According to Tavris and Aronson, the great popularizers of the concept of cognitive dissonance:

Conflict[s] of interest and politics are synonymous, and everyone understands the cozy collaboration that politicians forge to preserve their own power at the expense of the common welfare. It's harder to see that exactly the same process affects judges, scientists, and physicians, and other professionals who pride themselves on their ability to be intellectually independent for the sake of justice, scientific advancement, or public health. Their training and culture promote the core value of impartiality, so most people in these fields become indignant at the mere suggestion that financial or personal interests could contaminate their work. Their professional pride makes them see themselves as being above such matters. ${ }^{245}$

Lessig teases out the non-obvious ways our brains deal with COIs in corrupt institutions, by appealing to the research of social psychologist Sah and physician FughBerman, who showed that the Hippocratic oath and a commitment to professionalism do not insulate physicians from industry influence. ${ }^{246}$ Experiments showed that doctors often cannot distinguish between nonsense and obviously correct information in the face of modest perks offered by drug companies. It has long been shown that moral attitudes can change in the face of temptation. ${ }^{247}$ Professionals are encumbered by ethical blind spots that lead actors to confirm initial judgments even in the face of new data. ${ }^{248,249}$ Sah, with Lowenstein, ${ }^{250}$ showed how gifts can influence their recipients without the target's awareness, cementing bad judgments with obligations.

The psychologist, Jonathan Haidt, cautioned that while we may think that moral judgments are based on reason, they are frequently based on intuition and instant emotional responses. ${ }^{251,252}$ Post hoc reasoning can be crafted to support an intuitive response, making it seem as if the judgment was based on good reason all along. This alignment of reason and emotion makes it very difficult to change someone's moral judgments. ${ }^{253}$ This becomes harder still when individuals in a community are operating in concert because they have the same competing interests.

Two chemists should not have to advise two public university presidents, a legal scholar (Young) and a psychologist (Cauce), on how Lessig, a law professor, has summarized the psychology of institutional corruption in a recent issue of The Chronicle of Higher Education, a publication to which the presidents' offices likely subscribe. ${ }^{237}$ Nonetheless, Young said he could accept gifts without it affecting his judgment about the benefactor. ${ }^{196}$ Lessig would characterize Young's statement as an example of the "ethically tough guy assumption," the idea that only weak-willed people can be bent by the influence of money. According to evidence-based research, the ethically tough guy assumption "is completely false." 238 Consider the following exchange between then Provost Cauce and the Nature journalist Reich:

Reich: [H]ow do you at the University of Washington handle the institutional conflict of interest problem (basically the concern comes up in alleged misconduct cases that universities may prefer to protect their own faculty because it may have financial or reputation consequences to find them guilty)?

Cauce: There is no institutional conflict when it comes to serving the interests of science and of our country. ${ }^{155}$

Here, Cauce appears unaware that her active encouragement of large gifts from a scientist who published "ENP" placed her at the epicenter of an extraordinarily welldocumented case of ICOIs.

The UW administration and the UW department of chemistry were promised large sums of money and, in our view, behaved in a consistent and coordinated manner over a long period of time until they got it, or most of it, even at the risk of normalizing irresponsible scientific conduct. The UW's decisions described herein epitomize the concept of ICOIs; leaders carried colossal and systemic competing financial interests, according to our reading of the wealth of scholarly literature on ICOIs. Internal investigations, compromised by ICOIs, influenced external investigations, which validated the internal investigations. It was a closed circle.

At the same time, each week the average science faculty 
member must declare his or her own potential COIs while reviewing and submitting grants and journal articles. Annual or biannual university-wide COI disclosures must be signed and filed. This is but one symptom of a national system for adjudicating scientific misconduct that is incapacitated by contradiction. The present article underscores the necessity of reforming our system for ensuring ethical university research and developing comprehensive ICOI policies is a first step. These policies must apply explicitly to the highestranking members of the communities, as advocated clearly by Resnik, ${ }^{17,19}$ Krimsky, ${ }^{15,183}$ Slaughter, ${ }^{20,21}$ and many others, in addition to a number of professional science societies and organizations ${ }^{23,24,26,29,254}$ that have expressed growing concerns over absence of ICOI standards. According to the National Academies, academic leaders are responsible for:

sustaining a research culture that fosters integrity and encourages adherence to best practices... Should later events call into question the rigor of an institutional response to allegations of misconduct in research, top institutional leaders should be expected, as a matter of course, to examine the shortcomings of the process and share lessons learned with the larger community of scholars. Institutional leaders should reiterate the importance of critical standards such as appropriate authorship practices, data sharing, and complete reporting of results. ${ }^{254}$

On the academy and institutional corruption, Lessig sums it up this way: "There may be no demographic more primed for vulnerability [than the academic], given the motives and self-regard of those involved. There is therefore no demographic we need to police more carefully... The academy is thus the best context in which to understand the dynamics of this corruption." 238

On leaving Seattle in June 2009, BK was advised by the chemistry department chair Hopkins "to think again about how you might be communicating this story to outsiders." 255 This is precisely how we are communicating this story to outsiders.

Acknowledgements: The authors thank Steven Hyman, Esq., Jason Giamo, Esq., and Katherine George, Esq. for legal review of the manuscript.

Disclosures: The views expressed herein are those of the authors alone and not necessarily those of any other person, firm or entity. No funding supported the preparation of the manuscript.

\section{Notes}

i. As this paper was under review, a young Danish researcher who also published experiments not performed, ${ }^{6}$ lost her professorship and had her Ph.D. revoked. ${ }^{256}$

ii. There are numerous other inconsistencies that can only be reconciled by "ENP," but these are too technical to convey here. iii. The famed mystery writer Dorothy L. Sayers has her fictional detective, Lord Peter Wimsey, quoting this phrase from Snow's novel in Gaudy Night, written the very next year. ${ }^{257}$ Both Snow's The Search and Sayer's Gaudy Night are about academic fraud.

iv. LD had a large NSF grant from which BK had a subcontract, but he had even more money for comparable research from the Department of Defense, the Defense Advanced Research Projects Agency (DARPA), and the Ballistic Missile Defense Organization. ${ }^{49}$ At the time, military agencies wanted to supercharge the battlefields of Afghanistan and Iraq with smart soldiers communicating with information technologies. According to Wired magazine in 2003, "[T]he Pentagon seems poised for a high-tech approach, both in Iraq and going forward decades into the future. Its major thrust for weapons development, the Future Combat Systems initiative, leans heavily on "networked warfare" - the idea that every infantryman, every pilot, every drone and every general will share everything they see and hear over a new Internet for combat." 258

v. We believe that Kwiram is here referring to a DARPA grant on technology similar to that being supported by the NSF. See previous note.

vi. The title of the lecture, slightly altered, was borrowed from David Foster Wallace. ${ }^{259}$

vii. Many tens of millions of dollars are referenced throughout this document. We emphasize that there are two major money categories, the $\$ 100$ million dollars from grants, contracts and venture capital,260 and as much as $\$ 40$ million in personal gifts. These pots of money do not overlap. We are therefore speaking in the aggregate of a financial entanglement between LD and the UW that could be almost as much as $\$ 150$ million dollars by today.

viii. While the UW has no ICOI policy, we found the phrase "Institutional conflict of interest" once on the UW website in a Microsoft Word document entitled "Use of the UW IRB" [Institutional Review Board]. It reads, "Institutional conflict of interest: When UW institutional conflict exists with respect to the research as determined by the UW Office of Research, the conflict management plan does not require an external IRB to perform the IRB review and oversight." 261 This is the common invocation of ICOIs in the context of human subject's research. Compare with Penn State's extensive and generally applicable policy quoted at length above, ${ }^{33}$ or that of Northwestern University. ${ }^{186}$

ix. As discussed in section 2009-2011 above, this actually occurred in 2010.

x. Jang included the following footnote in his paper (number 13): "A number of reports on TCP chromophores appeared during the rather lengthy preparation period of this manuscript: (a) Firestone...(f) Leclercq, A.; Zojer, E.; Jang, S.-H.; Barlow, S.; Geskin, V.; Jen, A. K.-Y.; Marder, S. R.; Bredas, J. L. J. Chem. Phys. 2006, 124, 044510. (g) Kaneko, A.; Lu, Z.; Wang, H.; Twieg, R. J.; Mao, G.; Singer, K. D.; Kaino, T. Nonlinear Opt., Quantum Opt. 2005, 34, 45."

xi. The UW and Texas A\&M rank \#2 and \#4, respectively, in NSF R\&D expenditures for 2017.262 
xii. Laudably, Cauce recently returned $\$ 95,000$ of deferred compensation to the UW during a financial crisis. ${ }^{198}$

xiii. The NSF cited FOIA exemptions (b)(5), -(6), and/or -(7)C.

\section{References}

1. Lederman D. Amherst College professor Carleen Basler resigns over accusations of plagiarism [Internet]. Springfield (MA): MassLive Media; 2012 Sep 28 [updated 2012 Sep 28; cited 2019 Jan 15]. Available from: https://www.masslive.com/news/index.ssf/2012/09/amhers $\mathrm{t}$ college professor resi.html.

2. Schmidt P. UNLV fires professor for repeated plagiarism [Internet]. Washington: The Chronicle of Higher Education; Dec 2, 2014 [cited 2019 Jan 15]. Available from: http://www.chronicle.com/article/UNLV-Fires-Professorfor/150309.

3. Maffly B. 'Pattern of plagiarism' costs University of Utah scholar his job: Bahman Bakhtiari says he's a victim of discrimination, sanction is overly harsh [Internet]. Salt Lake City (UT): The Salt Lake City Tribune; 2011 Aug 18 [cited 2019 Jan 15]. Available from: http://archive. sltrib.com/story.php?ref=/sltrib/news/5237837778/bakhtiari-university-panel-plagiarism.html.csp.

4. Dalton LA, Dalton LL, Dalton LR. Paramagnetic relaxation in inorganic complexes. I. Inhomogeneous hyperfine broadening. Inorganica Chim Acta [Internet]. June 1967 [cited 2019 Jan 15];1(1):5-11. Available from: https://doi.org/10.1016/S0020-1693(00)93130-X.

5. Zhitnikov RA, Kolesnikov NV. Paramagnetic resonance of free atoms of the alkali metals $\mathrm{Na}, \mathrm{K}$, and $\mathrm{Rb}$, stabilized in a molecular matrix at liquid-nitrogen temperatures. Sov PhysSolid State [Internet]. October 1965 [cited 2019 Jan 15];7(4):927-30. Available from:

http://retractionwatch.com/wp-content/ uploads/2015/03/Zhitnikov-Soviet-Phys-SolidState.1965.pdf.

6. Communication from the Editor. Inorganica Chim Acta [Internet]. June 1967[cited 2019 Jan 15]; 1:492. Available from: https://doi.org/10.1016/S0020-1693(00)93229-8.

7. Firestone KA, Reid P, Lawson R, Jang SH, Dalton LR. Advances in organic electro-optic materials and processing. Inorganica Chim Acta [Internet]. 2004 Aug 26 [cited 2019 Jan 15];357(13):3957-66. Available from https://doi.org/10.1016/i.ica.2004.07.031. Retracted.

8. Retraction notice to "Advances in organic electro-optic materials and processing" [Inorganica Chimica Acta 357 2004 3957-3966]. Inorganica Chim Acta [Internet]. Feb 24, 2014 [cited 2019 Jan 15]; 411:212. Available from: https://doi.org/10.1016/j.ica.2014.01.004.

9. UW News. UW Chemistry to establish a prestigious postdoctoral fellowship thanks to $\$ 12$ million commitment from professor emeritus Larry Dalton and Nicole Boand [Internet]. Seattle (WA): University of Washington; Mar 23,
2017 cited 2019 Jan 15]. Available from: http:// www.washington.edu/news/2017/03/23/uw-chemistry-toestablish-a-prestigious-postdoctoral-fellowship-thanks-to12-million-commitment-from-professor-emeritus-larrydalton-and-nicole-boand/.

10. University of Washington. Contributor Lists [Internet]. Seattle (WA): University of Washington; 2016 [cited 2019 Jan 15]. Available from: http://www.washington.edu/ giving/files/2016/11/rtc-donor-roster-2016.pdf.

11. Kahr B. Email to Hopkins PB, Cauce AM, Young MK. 2012 Sep 21.

12. Washington State Legislature. Chapter 42.56 RCW: Public records act [Internet]. Olympia (WA): Washington State Legislature; [cited 2019 Jan 15]. Available from: http:// apps.leg.wa.gov/rcw/default.aspx?cite=42.56.

13. Resnik, DB, The Price of Truth, Oxford University Press, Oxford (GB) 2007.

14. Logue AW, Shrank I. An ignored conflict of interest [Internet]. Washington: Inside Higher Ed; 2015 Aug 3 [cited 2019 Jan 15]. Available from:

https://www.insidehighered.com/views/2015/08/03/essayconflicts-interest-regarding-faculty-members-and-curriculardecisions.

15. Krimsky S. Science in the Private Interest: Has the Lure of Profits Corrupted Biomedical Research? New York: Rowman and Littlefield Publishers; 2004.

16. Marcrina FL, editor. Scientific Integrity - Text and Cases in Responsible Conduct of Research. Washington DC, ASM Press, 2014, Chapter 7, Bradley SG. Competing interests in research; $p$ 209-41.

17. Resnik DB, Ariansen JL, Jamal J, Kissling GE. Institutional conflict of interest policies at U.S. academic research institutions. Acad Med [Internet]. 2016 Feb [cited 2019 Jan 15];91(2):242-6. Available from: https://www.ncbi.nlm.nih.gov/pmc/articles/PMC4731244/.

18. Nichols-Casebolt A, Macrina FL. Current perspectives regarding institutional conflict of interest: Commentary on "Institutional conflicts of interest in academic research." Sci Eng Ethics [Internet]. Oct 7, 2015 [cited 2019 Jan 15];1-7. Available from: https://doi.org/10.1007/s11948-015-9703-8.

19. Resnik DB, Shamoo AE. Conflict of interest and the university. Account Res [Internet]. Sep 8, 2002 [cited 2019 Jan 15];9(1):45-64. Available from: https://doi.org/10.1080/08989620210356.

20. Slaughter S, Feldman MP, Thomas SL. U.S. research universities' institutional conflict of interest policies. J Empir Res Hum Res Ethics [Internet]. Sep 1, 2009 [cited 2019 Jan 15];4(3):3-20. Available from: 
https://journals.sagepub.com/doi/abs/10.1525/jer.2009.4.3. 3.

21. Slaughter $\mathrm{S}$, Thomas SL, Johnson DR, Barringer SN. Institutional conflict of interest: The role of interlocking directorates in the scientific relationships between universities and the corporate sector. J High Educ [Internet]. Jan/Feb 2014 [cited 2019 Jan 15];85(1):1-35. Available from: doi.org/10.1080/00221546.2014.11777317.

22. Friedman PJ. The impact of conflict of interest on trust in science. Sci Eng Ethics [Internet]. 2002 Sep [cited 2019 Jan 15]; 8(3):413-20. Available from: doi.org/10.1007/s11948002-0063-9.

23. Harvard Law School Petrie-Flom Center. Institutional financial conflicts of interest in research universities [Internet]. Cambridge (MA): Petrie-Flom Center; Nov 2, 2012 [cited 2019 Jan 15]. Available from: http://petrieflom.law.harvard.edu/events/details/insituti onal-financial-conflicts-of-interest-in-researchuniversities.

24. Association of American Universities Task Force on Research Accountability. Report on individual and institutional financial conflict of interest [Internet]. Washington: Association of American Universities; Oct 2001[cited 2019 Jan 15]. Available from: https://www.aau.edu/sites/default/ files/AAU\%20Files/Key\%20Issues/Intellectual\%20Property/ Conflict-Interest-Rpt_Oct2001.pdf.

25. Hasselmo N. Individual and institutional conflict of interest: Policy review by research universities in the United States. Sci Eng Ethics [Internet]. Sep 2002[cited 2019 Jan 15];8(3):421-7. Available from: https://link.springer.com/article/10.1007/s11948-002-0064$\underline{8}$.

26. Association of American Medical Colleges Task Force on Financial Conflicts of Interest in Clinical Research. Protecting subjects, preserving trust, promoting progress II: Principles and recommendations for oversight of an institution's financial interests in human subjects research [Internet]. Washington: Association of American Medical Colleges; Oct 2002 [cited 2019 Jan 15]. Available from: http:// ccnmtl.columbia.edu/projects/rcr/rcr_conflicts/misc/Ref/ AAMC 2002ColReport.pdf.

27. Wilson RF. The death of Jesse Gelsinger: New evidence of the influence of money and prestige in human research. Am J Law Med [Internet]. Jun 1, 2010 [cited 2019 Jan 15];36(23):295-325. Available from: https://doi.org/10.1177/009885881003600202.

28. Elliott C. Institutional pathology and the death of Dan Markingson. Account Res [Internet]. Nov 3, 2016 [cited 2019 Jan 15]; 24(2):65-79. Available from: https://doi.org/ 10.1080/08989621.2016.1246969.

29. AAMC-AAU Advisory Committee. Protecting patients, preserving integrity, advancing health: Accelerating the implementation of COI policies in human subjects research [Internet]. Washington: Association of American Medical Colleges; Feb 2008 [cited 2019 Jan 15]. Available from: https://www.aamc.org/download/ 482216/data/protectingpatients.pdf.

30. Resnik DB. Institutional conflicts of interest in academic research, Sci Eng Ethics, 2015; 1-9. Available from: https://doi.org/10.1007/s11948-015-9702-9.

31. Caplan AL, Redman BK, editors. Getting to Good: Research Integrity in the Biomedical Sciences. Switzerland: Springer; 2018.

32. Moushey B, Dvorchak R. Game Over: Jerry Sandusky, Penn State, and the Culture of Silence. New York: William Morrow; 2012.

33. Pennsylvania State University. AD83 Institutional financial conflict of interest [Internet]. State College (PA): Pennsylvania State University; 2017 Jul 21 [cited 2019 Jan 15]. Available from: https://policy.psu.edu/policies/ad83.

34. Levinson DR. Institutional conflicts of interest at NIH grantees [Internet]. Washington: United States Department of Health and Human Services Office of Inspector General; Jan 2011 [cited 2019 Jan 15]. Available from: https:// oig.hhs.gov/oei/reports/oei-03-09-00480.pdf.

35. Reich ES. Plastic Fantastic: How the Biggest Fraud in Physics Shook the Scientific World. London: St. Martin's Press; 2010.

36. Zhitnikov and Kolesnikov (ref 5) passage-by-passage comparison with Dalton, Dalton, and Dalton (ref 4). (See appendix.)

37. Judson HF. The Great Betrayal: Fraud in Science. Orlando (FL): Harcourt; 2004.

38. Snow CP. The Search. Cornwall (GB): House of Stratus; 2000 (first pub. 1934).

39. 2003 ACS national award winners. Chem Eng News [Internet]. Jan 6, 2003 [cited 2019 Jan 15];81(2):44-50. Available from: http://pubs.acs.org/cen/awards/8102/8102awards.html.

40. Awards: Larry Dalton is Pauling medalist. Chem Eng News [Internet]. Sep 26, 2011 [cited 2019 Jan 15];89(39):39. Available from: https://pubs.acs.org/doi/abs/10.1021/cenv089n039.p039.

41. Baldwin B. Larry Dalton on photonics and electro-optics [Internet]. East Norriton (PA): Connected Social Media, L.L.C.; May 16, 2007 [cited 2019 Jan 15]. Available from: http://connectedsocialmedia.com/1280/larry-dalton-onphotonics-and-electro-optics/.

42. Robinson B. Email to Letter to Vanderbilt University Professor, name redacted, 2012, Oct 8.

43. Vanderbilt University Professor, Email to Kahr B. 2012, Sep 21.

44. Montgomery M. Email to Wu D. 1998, Dec 31.

45. Dietz M, Email to Montgomery Email, 2003 Jun 5.

46. Paulson T. Technological revolution is in the works at a UW lab [Internet]. Seattle (WA): Seattle-Post Intelligencer, Hearst Seattle Media, LLC; 2000 Apr 7 [cited 2019 Jan 15]. Available from: https://depts.washington.edu/eooptic/files/ seattlepi.pdf. 
47. Smith C. UW lands advanced tech center [Internet]. Seattle (WA): Seattle Post Intelligencer, Hearst Seattle Media, LLC; 2002 Apr 30 [cited 2019 Jan 15]. Available from: https://www.seattlepi.com/news/article/UW-landsadvanced-tech-center-1086358.php.

48. Photonics Media. $U$ of Washington photonics research awards could reach $\$ 100$ million [Internet]. Pittsfield (MA): Photonics Media; May 8, 2002 [cited 2019 Jan 15]. Available from: https://www. photonics.com/Article.aspx?AID=12708.

49. Stricherz V. NSF center designation puts UW on cutting edge [Internet]. Seattle (WA): University of Washington; May 2, 2002 [cited 2019 Jan 15]. Available from: http://www.washington.edu/news/2002/05/02/nsf-centerdesignation-puts-uw-on-cutting-edge/.

50. UW News. Breakthroughs in capacity, power consumption set to revolutionize photonics [Internet]. Seattle (WA): University of Washington; Feb 17, 2004 [cited 2019 Jan 15]. Available from: http://www.washington.edu/news/ 2004/02/17/breakthroughs-in-capacity-power-consumptionset-to-revolutionize-photonics/.

51. University of Washington. NSF award would seal UW position as information technology research leader [Internet]. Washington: American Association for the Advancement of Science; Apr 30, 2002 [cited 2019 Jan 15]. Available from:

https://www.eurekalert.org/pub_releases/2002-04/uownaw043002.php.

52. Dalton $L R$, Harper AW, Robinson BH. The role of London forces in defining noncentrosymmetric order of high dipole moment-high hyperpolarizability chromophores in electrically poled polymeric thin films. Proc Natl Acad Sci USA [Internet]. May 13, 1997 [cited 2019 Jan 15];94(10):4842-7. Available from: https://doi.org/10.1073/pnas.94.10.4842.

53. Dalton LR, Steier WH, Robinson BH, Zhang C, Ren A, Garner $\mathrm{S}$, et al. From molecules to opto-chips: organic electro-optic materials. J Mater Chem [Internet]. 1999 [cited 2019 Jan 15]; 9(9):1905-20. Available from: https://doi.org/10.1039/a902659b.

54. Robinson BH, Dalton LR, Harper AW, Ren A, Wang F, Zhang $C$, et al. The molecular and supramolecular engineering of polymeric electro-optic materials. Chem Phys [Internet]. July 1, 1999 [cited 2019 Jan 15];245(1-3):35-50. Available from: https://doi.org/10.1016/S0301-0104(99)00079-8.

55. National Science Foundation. Award Abstract \#0120967: Center on Materials and Devices for Information Technology Research [Internet]. Alexandria (VA): National Science Foundation; [cited Jan 15, 2019]. Available from: https:// www.nsf.gov/awardsearch/showAward?AWD ID=0120967.

56. Michl J, Thulstrup EW. Spectroscopy with Polarized Light: Solute Alignment by Photoselection, Liquid Crystal, Polymers, and Membranes Corrected Software Edition. 1st ed. Weinheim (DE): Wiley-VCH; 1995

57. Nordén B, Rodger A, Dafforn T. Linear Dichroism and Circular Dichroism: A Textbook on Polarized-Light Spectroscopy. London: Royal Society of Chemistry, 2010.
58. Kahr B, Gurney RW. Dyeing crystals. Chem Rev [Internet]. Mar 27, 2001 [cited 2019 Jan 15];101(4):893-951. Available from: https://doi.org/10.1021/cr980088n.

59. Cui X, Nichols SM, Arteaga O, Freudenthal J, Paula F, Shtukenberg AG, Kahr B. Dichroism in helicoidal crystals. J Am Chem Soc [Internet]. Sep 12, 2016 [cited 2019 Jan 15];138(37):12211-8. Available from: https://doi.org/10.1021/jacs.6b06278.

60. Nichols SM, Arteaga O, Martin A, Kahr B. Measurement of transmission and reflection from a thick anisotropic crystal modeled by a sum of incoherent partial waves. J. Opt. Soc. Am. A [Internet]. Nov 2015 [cited 2019 Jan 18]; 32(11):204957. Available from: http://dx.doi.org/10.1364/JOSAA.32.002049.

61. Hollingsworth MD. Letter to Young MK. Aug 21, 2012.

62. Moerner WE, Silence SM, Hache F, Bjorklund GC. Orientationally enhanced photorefractive effect in polymers. J Opt Soc Am B [Internet]. Feb 1994 [cited 2019 Jan 15]; 11(2):320-30. Available from: https://doi.org/10.1364/JOSAB.11.000320.

63. Moerner WE, Silence SM. Polymeric photorefractive materials. Chem Rev [Internet]. Jan 1, 1994 [cited 2019 Jan 15]; 94(1):127-55. Available from: https://doi.org/10.1021/cr00025a005.

64. Marder SR, Kippelen B, Jen AK-Y, Peyghambarian N. Design and synthesis of chromophores and polymers for electrooptic and photorefractive applications. Nature [Internet]. Aug 28, 1997 [cited 2019 Jan 15]; 388:845-51. Available from: https://doi.org/10.1038/42190.

65. Moerner WE, Grunnet-Jepsen A, Thompson CL. Photorefractive polymers. Annu Rev Mater Sci [Internet]. Aug 1997 [cited 2019 Jan 15];27(1):585-623. Available from: https://doi.org/10.1146/annurev.matsci.27.1.585.

66. Kippelen B, Marder SR, Hendrickx E, Maldonado JL, Guillemet G, Volodin BL, et al. Infrared photorefractive polymers and their applications for imaging. Science [Internet]. Jan 2, 1998[cited 2019 Jan 15];279(5347):54-7. Available from: http://science.sciencemag.org/content/279/ 5347/54.

67. Ostroverkhova O, Moerner WE. Organic photorefractives: Mechanisms, materials, and applications. Chem Rev [Internet]. Jun 26, 2004 [cited 2019 Jan 15];104(7):3267-314. Available from: https://doi.org/10.1021/cr960055c.

68. Meredith GR, VanDusen JG, Williams DJ. Optical and nonlinear optical characterization of molecularly doped thermotropic liquid crystalline polymers, Macromol. 1982; 15:1385-89. Available from: https://doi.org/10.1021/ma00233a033.

69. Brewster D. On a new property of light exhibited in the action of chrysammate of potash upon common and polarized light. Philo Mag [Internet]. 1846 [cited 2019 Jan 15];29(194):331-2. Available from: https://doi.org/10.1080/14786444608645512.

70. Wong L, Hu C, Paradise R, Zhu Z, Shtukenberg A, Kahr B. Relationship between tribology and optics in thin films of 
mechanically oriented nanocrystals. J Am Chem Soc [Internet]. 2012 Jun 26 [cited 2019 Jan 15];134(29):1224551. Available from: https://doi.org/10.1021/ja304799a.

71. Kahr B. Email to Kwiram A. 2004, Sep 30.

72. Kwiram A. Email to Kahr B, and replies. 2004, Sep 30.

73. Hopkins, PB, Email to Kahr B, 2004, Feb 12.

74. Kahr B. Email to Jen AK-Y 2004, Feb 17.

75. Kahr B. NSF Sub-report. 2004, not dated.

76. Reich ES. Electro-optic dye triggers ethics row: Dispute puts focus on reporting standards for major grants. Nature [Internet]. Sep 6, 2012 [cited 2019 Jan 15];489:17. Available from:

https://www.nature.com/polopoly fs/1.11346!/menu/main/ topColumns/topLeftColumn/pdf/489017a.pdf.

77. National Science Foundation Division of Behavioral and Cognitive Sciences, Social, Behavioral, and Economic Sciences Directorate. Tips and guidelines on the submission of effective annual, final, and project outcomes reports [Internet]. Alexandria (VA): National Science Foundation; [cited Jan 15, 2019]. Available from: https://www.nsf.gov/sbe/bcs/BCS_Reporting_Guidelines.pdf

78. Benedict JB. Dyeing Crystals: 19th Century Phenomenology To 21st Century Technology [dissertation] [Internet]. Seattle (WA): University of Washington; 2007 [cited 2019 Jan 15]. Available from: https://digital.lib.washington.edu/researchworks/handle/17 73/8636.

79. Marder SR, Kippelen B, Jen AK-Y, Peyghambarian N. Design and synthesis of chromophores and polymers for electrooptic and photorefractive applications. Nature [Internet]. Aug 28, 1997 [cited 2019 Jan 15];388(6645):845-51. Available from: https://doi.org/10.1038/42190.

80. Kahr B, Jackson JE, Ward DL, Jang SH, Blount JF. Comparison of twists in isosteric propellers: $X$-ray structures of tris $(2,6$ dimethoxyphenyl) borane, tris(2,6-dimethoxyphenyl) methyl cation and tris(2,6-dimethoxyphenyl) methyl radical. Acta Crystallogr B Struct Sci Cryst Eng Mater [Internet]. Jun 1992 [cited 2019 Jan 15];48(3):324-9. Available from: https://doi.org/10.1107/S0108768191014982.

81. Jang SH, Bertsch RA, Jackson JE, Kahr B. Interrupted $\sigma$-bonds in organic materials with colligative magnetic properties. Mol Cryst Liq Cryst [Internet]. Jan 1992 [cited 2019 Jan 15]; 211(1):289-303. Available from: https://doi.org/10.1080/10587259208025828.

82. Jang SH, Gopalan P, Jackson JE, Kahr B. Jacobson and Heintschel peroxides. Angew Chem Int Ed Engl [Internet]. Apr 18, 1994 [cited Jan 15, 2019]; 33(7):775-7. Available from: https://doi.org/10.1002/anie.199407751.

83. Rifani M, Yin YY, Elliott DS, Jay MJ, Jang SH, Kelley MP, Bastin L, Kahr B. Solid state dye lasers from stereospecific hostguest interactions. J Am Chem Soc [Internet]. July 1995[cited Jan 15, 2019]; 117(28):7572-3. Available from: https://doi.org/10.1021/ja00133a042.

84. Kahr B, Jang SH, Subramony JA, Kelley MP, Bastin L. Dyeing salt crystals for optical applications. Adv Mater [Internet].
Nov 1996 [cited 2019 Jan 15]; 8(11):941-4. Available from: https://doi.org/10.1002/adma.19960081117.

85. Jen AK-Y, Jang SH, Kahr B, inventors; University of Washington, assignee. Pyrroline chromophores. United States patent 7,307,173 B1. 2007 Dec 11.

86. Jang S-H. Emails to Firestone K, and related, 2005, Jan 31.

87. Kahr B. Emails to Jen AK-Y and related between Dalton L. and Jang S-H. 2003, Mar 12.

88. Dalton LR, Emails to Jang S-H, 2003, Mar 13-14.

89. Jang S-H. Email to Kahr B. 2004, May 7.

90. Dalton LR. Organic electro-optic materials. Pure Appl Chem [Internet]. 2004 Jan 1 [cited 2019 Jan 15];76(7-8):1421-33. Available from: https://doi.org/10.1351/pac200476071421.

91. Dalton LR, Jen AK-Y, Steier WH, Robinson BH, Jang SH, Clot $O$, et al. Organic electro-optic materials: Some unique opportunities. Proc SPIE Int Soc Opt Eng [Internet]. Jun 18, 2004 [cited Jan 15, 2019]; 5351:1-15. Available from: https://doi.org/10.1117/12.533167.

92. Dalton $L R$, Robinson $B H$, Jen $A K-Y$, Reid $P$, Eichinger $B$, Jang $\mathrm{SH}$, et al. Organic electro-optic materials. Proc SPIE Int Soc Opt Eng [Internet]. Dec 16, 2004 [cited Jan 15, 2019]; 5621:93-105. Available from: https://doi.org/10.1117/12.584102.

93. Dalton $L R$, Robinson $B H$, Jen $A K-Y$, Reid $P$, Eichinger $B$, Sullivan $P$, et al. Electro-optic coefficients of $500 \mathrm{pm} / \mathrm{V}$ and beyond for organic materials. Proc SPIE Int Soc Opt Eng [Internet]. Aug 30, 2005[cited Jan 15,2019]; 5935:5935020112. Available from: https://doi.org/10.1117/12.617343.

94. Jen A, Luo J, Kim TD, Chen B, Jang SH, Kang JW, et al. Exceptional electro-optic properties through molecular design and controlled self-assembly. Proc SPIE Int Soc Opt Eng [Internet]. Aug 18, 2005 [cited Jan 15, 2019]; 5935:59350601-13. Available from: https://doi.org/10.1117/12.620806.

95. American Chemical Society. Ethical guidelines to publication of chemical research [Internet]. Washington: American Chemical Society; [revised July 2015; cited 2019 Jan 15]. Available from: https://pubs.acs.org/userimages/ContentEditor/121805446 8605/ethics.pdf.

96. Jang S-H. Email to Kahr B. 2005 Feb 1.

97. Wilson EK. Electro-optics paper retracted [Internet]. Washington: American Chemical Society; Mar 10, 2014 [cited Jan 15,2019]. Available from: https://cen.acs.org/articles/92/i10/Electro-Optics-PaperRetracted.html.

98. Dalton LD, Email to Cauce AM. 2010, Sep 9.

99. Dalton LD, Email to Hopkins P. 2010, Sep 8.

100. Pepper E. Email to Kahr B. 2016, Jan 8.

101. Society of Photo-Optical Instrumentation Engineers. SPIE awards, special events will recognize contributions to optics and photonics [Internet]. Bellingham (WA): SPIE; Aug 7, 2008 [cited Jan 15, 2019]. Available from: http://spie.org/aboutspie/press-room/press-releases/op08-awards-8-7-08. 
102. Wallace PM, Sluss DRB, Dalton LR, Robinson BH, Reid PJ. Single-molecule microscopy studies of electric-field poling in chromophore-polymer composite materials. J Phys Chem B [Internet]. Jan 2006 [cited Jan 15, 2019];110(1):75-82. Available from: https://doi.org/10.1021/jp0546711.

103. Reid P. Email to Kahr B. 2010, May 11.

104. Sullivan PA, Rommel HL, Takimoto Y, Hammond SR, Bale DH, Olbricht BC, et al. Modeling the optical behavior of complex organic media: From molecules to materials. J Phys Chem B [Internet]. Nov 26, 2009 [cited Jan 15,2019];113(47):155818. Available from: https://doi.org/10.1021/jp908057d.

105. Olbricht BC, Sullivan PA, Dennis PC, Hurst JT, Johnson LE, Benight SJ, et al. Measuring order in contact-poled organic electrooptic materials with variable-angle polarizationreferenced absorption spectroscopy VAPRAS. J Phys Chem B. 2011; 1152:231-241. See especially reference 6. Available from: https://pubs.acs.org/doi/abs/10.1021/jp107995t.

106. Hopkins PB. Email to Robinson B 2012, Sep 5 and reply.

107. Oransky I. Leading chemist notches two retractions in one journal, separated by 47 years [Internet]. Retraction Watch; Feb 25, 2014 [cited Jan 15, 2019]. Available from: http:// retractionwatch.com/2014/02/25/leading-chemist-notchestwo-retractions-in-one-journal-separated-by-47-years/.

108. Long K. Rare choice: Could UW's next president come from within? [Internet]. Seattle (WA): The Seattle Times; Sep 26, 2015 [updated Sep 28, 2015; cited Jan 15, 2019]. Available from: https://www.seattletimes.com/seattlenews/education/supporters-of-interim-president-ana-maricauce-say-look-no-further-for-uws-next-leader-2/.

109. Goldblatt J. Email to Ayer W. Chair of Board of Regents, , Mar 19, 2015.

110. Cohen JS. After tumultuous year, U. of I. chancellor abruptly steps down [Internet]. Chicago (IL): Chicago Tribune; Aug 6, 2015 [cited Jan 15, 2019]. Available from: https:// www.chicagotribune.com/news/local/breaking/ct-universityof-illinois-chancellor-resigns-20150806-story.html.

111. Kahr B. Email to University Washington Board of Regents, Mar 16, 2015.

112. Stacey RC, Email to Chairs of the Departments in the College of Arts and Sciences. Mar 17, 2015.

113. Stacey RC. Email to Irving R. Mar 26,2015.

114. Stacey RC. Email to Dalton LR and Boand N. May 22,2015.

115. Stacey RC. Email to Dalton LR and Boand N. Dec 12, 2016.

116. Hardy S. GigOptix to go public through merger with Lumera [Internet]. Tulsa (OK): PennWell Corporation; Mar 28 ,2008 [cited Jan 15, 2019]. Available from: https:// www.lightwaveonline.com/articles/2008/03/gigoptix-to-gopublic-through-merger-with-lumera-54885707.html.

117. Gigpeak, Inc. (1432150) SEC Filing 10-K annual report for the fiscal year ending Saturday, December 31, 2016 [Internet]. Tustin (CA): Idea Edge Industries, LLC; Mar 15, 2017 [cited Jan 15, 2019]. Available from: https://www.last10k.com/secfilings/1432150\#fullReport.
118. Hardy S. Lightwave Logic reports progress on 50-Gbps polymer modulator, eyes $100 \mathrm{Gbps}$ [Internet]. Tulsa (OK): PennWell Corporation; Aug 30,2018 [cited Jan 15, 2019]. Available from: https://www.lightwaveonline.com/ articles/2018/08/lightwave-logic-reports-progress-on50gbps-polymer-modulator-eyes-100-gbps.html.

119. Kwiram A, The next big thing, ChemLetter [Internet]. Seattle (WA): University of Washington; 2016 Summer [cited Jan 15, 2019]. Available from: https://depts.washington.edu/chem/ newsevents/documents/2016SummerChemLetter.pdf.

120. Dalton LR, Günter $P$, Jazbinsek $M$, Kwon OP, Sullivan PA. Organic Electro-Optics and Photonics: Molecules, Polymers, and Crystals. Cambridge (GB): Cambridge University Press; 2015.

121. Eustis S. Optical modulators poised for explosive market growth, [Internet]. Winter Green Research (MD); Market Research.com, Sep 24, 2018 [cited Jan 18]. Available from: https://blog.marketresearch.com/optical-modulatorspoised-for-explosive-market-growth.

122. Boand Family Foundation [Internet]. Williamsburg (VA): GuideStar USA; [cited Jan 15, 2019]. Available from: https:// www.guidestar.org/profile/95-4262373.

123. University of Washington Public Records Release, Dalton gifts PR-2017-00615 Release. 2017. Aug 25. 2018 p.

124. Dryfoos W. Email to Kravas C. et al. Jun 4, 2003.

125. Kahr B. Email to Cauce AM. Jun 18, 2010.

126. Cauce AM. Memorandum to Dalton LR. Oct 7, 2010.

127. Michigan State University College of Natural Sciences, Connections. Winter, 2007.

128. Michigan State University College of Natural Sciences, Connections. Fall, 2008.

129. Michigan State University College of Natural Sciences, Connections. 2014.

130. Michigan State University College of Natural Sciences. Donors. Jul 1, 2015-Jun 30, 2016.

131. Michigan State University College of Natural Sciences. Donor Honor Roll, Jul 1, 2016-Jun 30, 2017. [Internet]. East Lansing (MI): Michigan State University; [Jan 15, 2019]. Available from: https://natsci.msu.edu/about/giving/donor-honorroll/.

132. Hopkins PB. Email to Chemistry Faculty, Feb 16, 2007.

133. Hopkins PB. Email to Sales L. Apr 14, 2010.

134. Yen J. Email to Salterwhite M. Jan 15, 2002.

135. Brown DP. Interdepartmental memorandum to Severson JA, May 26, 2005.

136. LUMERA CORP (LMRA) IPO [Internet]. New York: The NASDAQ Stock Market; [cited Jan 15, 2019]. Available from: https://www.nasdaq.com/markets/ipos/company/lumeracorp-163841-39568.

137. University of Washington Public Records Release, 13-00445, Apr 28, 2014

138. University of Washington Public Records Release, 16-00080 Nov 9, 2016. 2,627 pages. 
139. University of Washington Public Records Release, PR-201700615. Aug 25,2017. 8 pages.

140. Superior Court of the State of Washington, Bart Kahr v. University of Washington, No. 17-2-28759-8 SEA, 2017. (not included in appendix)

141. University of Washington Public Records Release, King County Cause No. 17-2-28759-8, Feb 5, 2018. 3014 pages.

142. University of Washington Public Records Release, King County Cause No. 17-2-28759-8, Mar 6,2018. 353 pages.

143. University of Washington Rules Coordination Office. Executive Order No. 32: Employee Responsibilities and Employee Conflict of Interest [Internet]. Seattle (WA): University of Washington; [modified May 19, 2017; cited Jan 15, 2019]. Available from: http://www.washington.edu/admin/rules/policies/PO/EO 32.html.

144. Resnik DB. Email to Kahr B. May 9, 2017.

145. Ehrlinger J, Gilovich T, Ross L. Peering into the bias blind spot: People's assessments of bias in themselves and others. Pers Soc Psychol Bull [Internet]. May 1, 2005 [cite 2019 Jan 15]; 31(5):680-92. Available from: https://doi.org/10.1177/0146167204271570.

146. Pronin E, Lin DY, Ross L. The bias blind spot: Perceptions of bias in self versus others. Pers Soc Psychol Bull [Internet]. Mar 1, 2002 [cited Jan 15, 2019]; 28(3):369-81. Available from: https://doi.org/10.1177/0146167202286008.

147. Kahr B. Email to Cauce AM, Jun 21, 2010.

148. Kahr B. Email to Stacey RC, Mar 23, 2015.

149. Cauce, AM. Email to Kahr B. and replies, Jun 19, 2010.

150. Ackenhusen A. Letter to Kahr B. Jun 19, 2010.

151. Cauce AM. Letter to Kahr B. Jul 7, 2011.

152. Stuetzle W. Email to Cauce AM. Jun 12, 2010.

153. Stacey RC. Email to Stuetzle W. Jul 9, 2013.

154. Oliver L. Email to Riskin EA, Cauce AM. Jul 29, 2010.

155. Cauce AM. Emails with Reich E. Aug 21, 2012.

156. Kahr B. Letter to Cauce AM. Jul 21, 2011.

157. National Science Foundation Office of Integrative Activities. STC annual reporting requirements and instructions [Internet]. Alexandria (VA): National Science Foundation; [cited Jan 15, 2019]. Available from: https://www.nsf.gov/ od/oia/programs/stc/reports/reportingrequirements.pdf.

158. University of Washington Science and Technology Center, Materials and Devices for Information Technologies Research, Annual Progress Report, 2006. (Long document not included in appendix. Those portions we hold are available on request from $\mathrm{BK}$ ).

159. Strevens $M$. The role of the priority rule in science. J Philo [Internet]. Feb 2003 [cited Jan 15, 2019]; 100(2):55-79. Available from: http://www.jstor.org/stable/3655792.

160. Ducor, P. Coauthorship and coinventorship, Science [Internet]. Aug 11,2000 [cited Jan 19, 2019]; 289:874-5.
Available from:

https://science.sciencemag.org/content/289/5481/873.

161. Jang SH, Luo J, Tucker NM, Leclercq A, Zojer E, Haller MA, et al. Pyrroline chromophores for electro-optics. Chem Mater [Internet]. Jun 1, 2006 [cited Jan 15, 2019]; 18(13):2982-8. Available from: https://doi.org/10.1021/cm052861i.

162. Erratum to: "Advances in organic electro-optic materials and processing" by Kimberly A. Firestone, Philip Reid, Rhys Lawson, Sei-Hum Jang, and Larry R. Dalton [Inorganica Chimica Acta, 357 (2004) 3957-3966]. Inorganica Chim Acta [Internet]. Jun 1, 2005[ctied Jan 15, 2019]; 358(9):2839. Available from: https://doi.org/10.1016/j.ica.2005.03.047.

163. Cauce AM. Emails to Dalton LR. Sep 20, 2010.

164. UW Video. UW Provost Town Hall: February 24, 2015 [Internet]. San Bruno (CA): YouTube, LLC; Feb 25, 2015 [cited Jan 15, 2019]. Available from: https://www.youtube.com/ watch?v=F7GkKIs8N50. See minute 14:50.

165. Washington State Legislature. Chapter 42.36 RCW: Appearance of fairness doctrine-limitations [Internet]. Olympia (WA): Washington State Legislature; [cited Jan 15, 2019]. Available from:

http://app.leg.wa.gov/rcw/default.aspx?cite=42.36.

166. Municipal Research and Services Center. Appearance of fairness doctrine [Internet]. Seattle (WA): MRSC of Washington; [modified Aug 31, 2018; cited Jan 15, 2019]. Available from: http://mrsc.org/Home/ExploreTopics/Legal/Ethics-Fairness-Conflicts-of-Interest/TheAppearance-of-Fairness-Doctrine.aspx.

167. University of Washington Rules Coordination Office. Executive Order No. 61 Research misconduct policy [Internet]. Seattle (WA): University of Washington; [modified May 19, 2017; cited Jan 15, 2019]. Available from: http://www.washington.edu/admin/rules/policies/PO/EO61. html.

168. Ackenhusen A. Handwritten note. July 2010.

169. Fisher RA. The Design of Experiments. 8th ed. New York: Hafner Publishing Co., Inc.; 1971, pp. 15-17.

170. United States Government Publishing Office. [Code of Federal Regulations, Tittle 45, Part VI, Section §689.4] [Internet]. Washington: United States Government Publishing Office; Oct 1, 2012 [cited Jan 15, 2019]. Available from: https://www.gpo.gov/fdsys/pkg/CFR-2017-title45vol3/pdf/CFR-2017-title45-vol3-sec689-4.pdf.

171. Kahr B. Letter to Ackenhusen A. Aug 4, 2010.

172 Jang S-H. Email to Kahr B. Feb 5, 2005.

173. Kelley MP, Janssens B, Kahr B, Vetter WM. Recognition of dyes by $\mathrm{K}_{2} \mathrm{SO}_{4}$ crystals: Choosing organic guests for simple salts. J Am Chem Soc [Internet]. Jun 1, 1994 [cited Jan 15, 2019]; 116(12):5519-20. Available from: https://doi.org/10.1021/ja00091a086.

174. Mitchell CA, Lovell S, Thomas K, Savickas P, Kahr B. Charge transfer interactions in dyed crystals of aromatic carboxylic acids and their relevance to MALDI mass spectrometry. Angew Chem Int Ed Engl [Internet]. May 20, 1996 [cited Jan 
15, 2019]; 35(9):1021-3. Available from: https://doi.org/ 10.1002/anie.199610211.

175. Lovell S, Subramony P, Kahr B. Poppy acid: Synthesis and crystal chemistry. J Am Chem Soc [Internet]. Aug 1, 1999 [cited Jan 15, 2019]; 121(30):7020-5. Available from: https://doi.org/10.1021/ja990402a.

176. Gurney RW, Mitchell CA, Ham S, Bastin LD, Kahr B. Salting benzenes. J Phys Chem B [Internet]. Feb 1, 2000 [cited Jan 15, 2019]; 104(5):878-92. Available from: https://doi.org/10.1021/.jp992424p.

177. Oransky I. Reports of misconduct investigations can tell us a lot. Here are more than a dozen of them [Internet]. [place unknown]: Retraction Watch; Jul 2, 2018 [cited Jan 15, 2019]. Available from: https:// retractionwatch.com/2018/07/02/reports-of-misconductinvestigations-can-tell-us-a-lot-here-are-more-than-a-dozenof-them/.

178. Oransky I. Misconduct investigation reports are uneven at best. Here's how to make them better [Internet]. [place unknown]: Retraction Watch; Mar 12, 2018 [cited Jan 15, 2019]. Available from:

https://retractionwatch.com/2018/03/12/misconductinvestigation-reports-are-uneven-at-best-heres-how-tomake-them-better/.

179. Ackenhusen A. Handwritten note. 2010. n.d.

180. United States Patent and Trademark Office. 2137 Pre-AIA 35 U.S.C. 102(f) [R-08.2017]: Pre-AIA 35 U.S.C. 102 Conditions for patentability; novelty and loss of right to patent [Internet]. Alexandria (VA): United States Patent and Trademark Office; [modified Jan 24, 2018; cited Jan 15, 2019]. Available from: https://www.uspto.gov/web/offices/pac/mpep/s2137.html.

181. Young MK. Email to University of Washington Community, Jan 3, 2012.

182. Young MK. Email to Johnson JG, Sep 5, 2012.

183. Turk JL, editor. Academic Freedom in Conflict: The Struggle Over Free Speech Rights in the University. Toronto: James Lorimer \& Co.; 2014. Krimsky S. Academic freedom, conflicts of interest and the growth of university-industry collaborations; p. 231-49.

184. University of Washington. Financial conflict of interest (FCOI) [Internet]. Seattle (WA): University of Washington; [cited Jan 15, 2019]. Available from: https://www.washington.edu/ research/compliance/financial-conflicts-of-interest-fcoi/.

185. Shamoo AE, Resnik DB. Responsible Conduct of Research. Oxford (GB): Oxford University Press; 2015.

186. Northwestern University Conflict of Interest Office. Institutional conflict of interest in research [Internet]. Evanston (IL): Northwestern University; Jan 13, 2014 [cited Jan 15, 2019]. Available from: http://www.northwestern.edu/coi/policy/institutional polic y.pdf.

187. Washington State Legislature. Chapter 42.52 RCW: Ethics in public service [Internet]. Olympia (WA): Washington State
Legislature; [cited Jan 15, 2019]. Available from: https:// app.leg.wa.gov/RCW/default.aspx?cite $=42.52 \&$ full=true.

188. Kahr B. Emails to De Leon M. Washington State Executive Ethics Board, Sep 27,2012, 28.

189. Washington State Executive Ethics Board [homepage on the Internet]. Olympia (WA): Washington State / Executive Ethics Board; [cited Jan 15, 2019]. Available from: https://ethics. wa.gov/.

190. De Leon M. Letter to Kahr B. Jan 22, 2014.

191. De Leon M. Washington State Executive Ethics Board Report to Kahr B. May 11, 2012.

192. American Association of University Professors. Policy Documents and Reports [Internet]. Baltimore (MD): Johns Hopkins University Press; 2014 [cited May 11, 2019]. Available from: https://muse.jhu.edu/book/39933.

193. Johnson JG. Email to Cordova R and Ikeda, G. Mar 21, 2012.

194. Cordova R. Letter Killeen D, Washington State Executive Ethics Board, Mar 23, 2012.

195. Amit E, Koralnik J, Posten AC, Muethel M, Lessig L. Institutional corruption revisited: exploring open questions within the institutional corruption literature. South Calif Interdiscip Law J [Internet]. 2017 [cited Jan 15, 2019]; 26:447-68. Available from: https://heinonline.org/HOL/LandingPage?handle=hein.journ als $/$ scid26\&div=26\&id=\&page=

196. Young MK. Letter to Killeen D, Washington State Executive Ethics Board, Mar 20, 2012.

197. Government Salaries Explorer. Michael K. Young [Internet]. Austin (TX): The Texas Tribune; [updated Jun 22, 2018; cited Jan 15, 2019]. Available at: https://salaries.texastribune.org/texas-am-university/ michael-k-young/1773944/.

198. Long K. Amid worsening financial picture, UW President Ana Mari Cauce returns $\$ 95 \mathrm{~K}$ in deferred compensation [Internet]. Seattle (WA): The Seattle Times; July 17, 2018 [updated Jul 19, 2018; cited Jan 15, 2019]. Available from: https://www.seattletimes.com/seattlenews/education/amid-worsening-financial-picture-uwpresident-ana-mari-cauce-returns-95K-in-deferredcompensation/.

199. Selingo J, Clark C, Cheng S. Pathways to the university presidency: The future of higher education leadership [Internet]. London: Deloitte Insights; Apr 18, 2017 [cited Jan 15, 2019]. Available from: https://www2.deloitte.com/insights/us/en/industry/publicsector/college-presidency-higher-education-leadership.html.

200. Hubbard v. Spokane County: Supreme Court of Washington, En Banc. Wallis D. Hubbard, Petitioner, v. Spokane County, Steve Hasson, Phil Harris, and James Manson, Respondent. No. 70975-1. Decided: July 18, 2002 [Internet]. Eagan (MN): Thomson Reuters; [cited Jan 15, 2019] Available from: http://caselaw.findlaw.com/wa-supremecourt/1340271.html.

201. University of Washington Attorney General's Office. Requests for legal services [Internet]. Seattle (WA): 
University of Washington; [cited Jan 15, 2019]. http:// www.washington.edu/admin/ago/legalservices.html.

202. Washington State Executive Ethics Board. Who we are [Internet]. Olympia (WA): Washington State / Executive Ethics Board; [cited Jan 15, 2019]. Available from: https:// ethics.wa.gov/about-us/who-we-are.

203. Robertson CT, Kesselheim, AS editors, Blinding as a Solution to Bias, Robertson CT. Why blinding? How blinding? A theory of blinding and its application to institutional corruption, Amsterdam, Elsevier, 2016, pp. 25-38.

204. This letter was co-authored by the Massachusetts Attorney General Martha Healy. Ferguson B, Healy M. AG Ferguson urges Acting Attorney General Whitaker to recuse himself from the Mueller investigation in multistate letter, Washington State Office of the Attorney General. Available from: https://www.atg.wa.gov/news/news-releases/agferguson-urges-acting-attorney-general-whitaker-recusehimself-mueller.

205. Kahr B, Letter to Fischer P, Ying C. Jan 11, 2011.

206. National Science Foundation Office of Inspector General, Office of Investigations. Closeout memorandum: Case Number: A11010003 [Internet]. Alexandria (VA): National Science Foundation; Mar 10, 2013 [cited Jan 15, 2019]. Available from: https://www.nsf.gov/oig/case-closeout/ A11010003.pdf.

207. National Science Foundation Office of Inspector General. FOIA Information: Obtaining a closeout memorandum or investigation report for an NSF OIG case [Internet]. Alexandria (VA): National Science Foundation; [cited Jan 15, 2019]. Available from: https://www.nsf.gov/oig/regulations/ foia.jsp.

208. What is FOIA? [Internet]. Washington: United States Department of Justice Office of Information Policy (OIP); [cited Jan 15,2019]. Available from: https://www.foia.gov/about.html.

209. Bross SW. Letter to Kahr B. Aug 21, 2013.

210. FOIAdvocates. FOIA exemptions [Internet]. Corvallis (OR): FOIAdvocates; [cited Jan 15,2019]. Available from: http://www.foiadvocates.com/exemptions.html.

211. Chason K. Letter to Kahr B, Sep 17, 2013.

212. Rudolph L. Letter to Kahr B. Nov 7, 2013.

213. Hopkins PB. Email to Reid P. Sep 5, 2012.

214. Rudolph L. Email to Kahr B. May 20, 2016.

215. National Science Foundation. MPS distinguished lecture by Prof. Bart Kahr (NYU) on optical crystallography in the 21st century [Internet]. Alexandria (VA): National Science Foundation; Dec 15, 2014 [cited Jan 15,2019]. Available from: https://www.nsf.gov/news/mmg/mmg disp.jsp? med id $=78261$.

216. National Science Foundation. Award Abstract \#1303080: Systematic theory-guided nano-engineering of desired order and viscoelasticity in electroactive dendrimers and polymers [Internet]. Alexandria (VA): National Science Foundation; [cited Jan 15, 2019]. Available from: https://www.nsf.gov/ awardsearch/showAward?AWDID=1303080.

217. Kevles D. The Baltimore Case: A Trial of Politics, Science, and Character. New York: Norton; 1998.

218. Buzzelli DE. The definition of misconduct in science: A view from NSF. Science [Internet]. Jan 29, 1993 [cited Jan 15, 2019]; 259(5095):584-589,647-648. Available from: https:// www.jstor.org/stable/2882851.

219. Panel on Scientific Responsibility and the Conduct of Research Committee on Science, Engineering, and Public Policy National Academy of Sciences National Academy of Engineering Institute of Medicine. Responsible Science, Volume I: Ensuring the Integrity of the Research Process [Internet]. Washington: National Academy Press; 1992 [cited Jan 15, 2019]. Available from: https://www.nap.edu/read/ 1864/chapter/1.

220. Smith DO. Managing the Research University. Oxford (GB): Oxford University Press; 2011.

221. Kulynych J. Intent to deceive: Mental state and scienter in the new uniform federal definition of scientific misconduct. Stanf Technol Law Rev [Internet]. 1998 [cited Jan 15, 2019] 2:34-68. Available from: https://heinonline.org/HOL/LandingPage?handle=hein.journ als/stant|r1998\&div=3\&id=\&page $=$.

222. Parrish D. Scientific misconduct and the plagiarism cases. J Coll Univ Law [Internet]. 1995 winter [cited Jan 15, 2019]; 21(3):517-54. Available from: https://eric.ed.gov/?id=EJ503324.

223. Keränen L. Assessing the seriousness of research misconduct: Considerations for sanction assignment. Account Res [Internet]. Aug 17, 2006 [cited Jan 15, 2019]; 13(2):179-205. Available from: https://doi.org/10.1080/08989620500440261.

224. DuBois JM, Andersen EE, Chibnall J. Assessing the need for a research ethics remediation program. Clin Transl Sci [Internet]. Feb 11, 2013 [cited Jan 15, 2019];6(3):209-13. Available from: https://doi.org/10.1111/cts.12033.

225. Kaiser J. Top U.S. Scientific misconduct officer quits in frustration with bureaucracy [Internet]. Washington: American Association for the Advancement of Science; Mar 12, 2014 [cited Jan 15, 2019]. Available from: http://www.sciencemag.org/news/2014/03/top-usscientific-misconduct-official-quits-frustration-bureaucracy.

226. Fischer P. New research misconduct policies. [Internet]. Alexandria (VA): National Science Foundation Office of Inspector General; [cited Jan 15, 2019]. Available from: https://www.nsf.gov/oig/ pdf/presentations/session.pdf.

227. Chisholm P. Olivieri medical dispute settled [Internet]. Toronto (ON): Historica Canada; 2003 Mar 17 [edited Dec 16, 2013; cited Jan 15, 2019]. Available from: https:// www.thecanadianencyclopedia.ca/en/article/olivierimedical-dispute-settled.

228. Viens AM, Savulescu J. Introduction to the Olivieri symposium. J Med Ethics [Internet]. Feb 1, 2004 [cited Jan 
15, 2019]; 30(1):1-7. Available from:

http://dx.doi.org/10.1136/jme.2003.006577.

229. Gariepy KD. Power, Discourse, Ethics: A Policy Study of Academic Freedom. Rotterdam (NL): Sense Publishing; 2015.

230. Shuchman M. The Drug Trial: Nancy Olivieri and the Science Scandal that Rocked the Hospital for Sick Children. Toronto (ON): Random House Canada; 2005.

231. Turk J, editor. The Corporate Campus: Commercialization and the Dangers to Canada's Colleges and University. Toronto (ON): James Lorimer; 2000. Olivieri N. When money and truth collide; pp. 53-62.

232. Michaels D. Doubt is Their Product: How Industry's Assault on Science Threatens Your Health. Oxford (GB): Oxford University Press; 2008.

233. Oreskes N, Conway EM. Merchants of Doubt: How a Handful of Scientists Obscured the Truth on Issues from Tobacco Smoke to Global Warming. New York: Bloomsbury Press.

234. Alford CF. Whistleblowers: Broken Lives and Organizational Power. Ithaca (NY): Cornell University Press; 2001.

235. Goode E. When DNA evidence suggests 'innocent,' some prosecutors cling to 'maybe' [Internet]. New York: The New York Times Company; Nov 15, 2011 [cited Jan 15, 2019]. Available from: https://www.nytimes.com/2011/11/16/us/dna-evidence-ofinnocence-rejected-by-some-prosecutors.html.

236. Festinger L. A Theory of Cognitive Dissonance. Stanford (CA): Stanford University Press; 1957.

237. Lessig L. How academic corruption works [Internet]. Washington: The Chronicle of Higher Education; 2018 Oct 7 [cited Jan 15, 2019]. Available from: https:// www.chronicle.com/article/How-Academic-CorruptionWorks/244703.

238. Lessig L. America, Compromised. Chicago: University of Chicago Press; 2018.

239. Thompson DF. Mediated corruption: The case of the Keating Five. Am Polit Sci Rev [Internet]. Jun 1993[cited Jan 15, 2019]; 87(2):369-81. Available from: https://doi.org/10.2307/2939047.

240. Thompson DF. Ethics in Congress: From Individual to Institutional Corruption. Washington: Brookings Institution; 1995.

241. Thompson DF. Theories of institutional corruption. Annu Rev Polit Sci [Internet]. May 11, 2018 [cited Jan 15, 2019]: 21(1);495-513. Available from: https://doi.org/10.1146/annurev-polisci-120117-110316.

242. Lessig L. Foreward: "Institutional corruption" defined. J Law Med Ethics [Internet]. Oct 1, 2013 [cited Jan 15, 2019]; 41(3):553-5. Available from: https://doi.org/10.1111/jlme.12063.

243. Teachout Z. Corruption in America: From Benjamin Franklin's Snuff Box to Citizens United. Cambridge (MA): Harvard University Press; 2014.
244. Mazar N. Amir O, Ariely D. The dishonesty of honest people: A theory of self-concept maintenance. J Market Res [Internet]. Dec 2008 [cited Jan 15, 2019];45(6):633-44. Available from: https://doi.org/10.1509/imkr.45.6.633.

245. Tavris C, Aronson E. Mistakes Were Made (But Not by Me): Why We Justify Foolish Beliefs, Bad Decisions, and Hurtful Acts. 3rd ed. London: Printer Martin Ltd; 2015.

246. Sah S, Fugh-Berman A. Physicians under the influence: Social psychology and industry marketing strategies. J Law Med Ethics [Internet]. Oct 1,2013 [cited Jan 15, 2019]; 41(3):66572. Available from: https://doi.org/10.1111/jlme.12076.

247. Mills J. Changes in moral attitudes following temptation. J Pers [Internet]. Dec 1958 [cited Jan 15, 2019]; 26(4):517-31. Available from: https://doi.org/10.1111/j.14676494.1958.tb02349.x.

248. Bazerman MH, Tenburnsel AE. Blind Spots: Why We Fail to Do What's Right and What to Do about It. Princeton (NJ): Princeton University Press, 2011.

249. Sezer O, Gino F, Bazerman MH. Ethical blind spots: explaining unintentional unethical behavior. Curr Opin Psychol [Internet]. Dec 2015 [cited Jan 15, 2019]; 6:77-81. Available from:

https://www.hbs.edu/faculty/Publication\%20Files/Ethical+B| ind+Spots 4db0de5b-5177-457d-be51-7f0d5d9f3f12.pdf.

250. Sah S, Loewenstein G. Effect of reminders of personal sacrifice and suggested rationalizations on residents' selfreported willingness to accept gifts: A randomized trial. JAMA [Internet]. Sep 15, 2010 [cited Jan 15, 2019]; 304(11):1204-11. Available from: https://jamanetwork.com/ journals/jama/fullarticle/186583.

251. Haidt J. The emotional dog and its rational tail: A social intuitionist approach to moral judgment. Psychol Rev [Internet]. Oct 2001 [cited Jan 15, 2019];108(4):814-34. Available from: http://dx.doi.org/10.1037/0033295X.108.4.814.

252. Haidt J. The Righteous Mind: Why Good People Are Divided by Politics and Religion. New York: Pantheon Books; 2012.

253. Tessman L. When Doing the Right Thing Is Impossible. Oxford (GB): Oxford University Press; 2017.

254. National Academies of Science, Engineering, and Medicine Committee on Responsible Science Committee on Science, Engineering, Medicine, and Public Policy, Policy and Global Affairs. Fostering Integrity in Research [Internet].

Washington: The National Academies Press; 2017 [cited Jan 15, 2019]. Available from:

https://www.nap.edu/read/21896/chapter/1.

255. Hopkins PB. Email to Kahr B. Jun 19, 2009.

256. University of Copenhagen, The University of Copenhagen revokes doctoral degree [Internet]. Copenhagen: University of Copenhagen; Sep 12, 2017 [cited Jan 15, 2019]. Available from: https://news.ku.dk/all news/2017/09/the-universityof-copenhagen-revokes-doctoral-degree/.

257. Sayers, DL. Gaudy Night, Harper Paperbacks, 2012 (first pub 1935). 
258. Shachtman N. Taking aim at military technology [Internet]. New York: Condé Nast; Mar 19, 2003 [cited Jan 15, 2019]. Available from: https://www.wired.com/2003/03/takingaim-at-military-technology/.

259. Wallace DF, Infinite Jest, Little Brown: Boston; 1996.

260. Scalise M, Lumera completes $\$ 24$ million round of financing, Lightwave, Mar 15, 2001. Available from:

https://www.lightwaveonline.com/articles/2001/03/lumeracompletes-24-million-round-of-financing-53467747.html.
261. University of Washington Human Subjects Division. SOP use of the UW IRB [Internet]. Seattle (WA): University of Washington; [updated Sep 8, 2017; cited Jan 15, 2019]. Available from: https://www.washington.edu/ research/policies/sop-use-of-the-uw-irb-2/.

262. Federally financed higher education R\&D expenditures, financed by the National Science Foundation, ranked by NSF R\&D expenditures, by R\&D field: FY 2017. Available from: https://ncsesdata.nsf.gov/herd/2017/ (see table 63). 